\title{
Vertical dust mixing and the interannual variations in the Mars thermosphere
}

\author{
Jared M. Bell, ${ }^{1}$ Stephen W. Bougher, ${ }^{1}$ and James R. Murphy ${ }^{2}$ \\ Received 8 November 2006; revised 31 May 2007; accepted 13 August 2007; published 11 December 2007.
}

[1] Mars winter polar warming is a phenomenon of the lower thermosphere temperatures and densities that is well documented by in situ accelerometer data taken during spacecraft aerobraking maneuvers. Previous work by Bougher et al. (2006) simulates two specific time periods, corresponding to existing aerobraking data sets, and confirms the existence of winter polar warming structures in the Martian upper atmosphere, using the coupled Mars General Circulation Model-Mars Thermosphere General Circulation Model (MGCM-MTGCM). The present work investigates the underlying mechanisms that drive winter polar warming in three major studies: (1) a systematic analysis of vertical dust mixing in the lower atmosphere and its impact upon the dynamics of the lower thermosphere (100-130 km), (2) an interannual investigation utilizing 3 years of lower atmosphere infrared (IR) dust optical depth data acquired by the Thermal Emission Spectrometer (TES) instrument on board Mars Global Surveyor (MGS), and finally (3) a brief study of the MTGCM's response to variations in upward propagating waves and tides from the lower atmosphere. From the first study, we find that the vertical dust mixing greatly modifies the simulated winter polar warming features in the MTGCM's thermosphere at both solstice seasons. Furthermore, this sensitivity study confirms that an interhemispheric Hadley circulation and the concomitant adiabatic heating rates are the primary causes for these winter polar warming structures. From the second study, we find that as revealed in the lower atmosphere by Liu et al. (2003), the polar lower thermosphere exhibits a high degree of variability at $\mathrm{L}_{S}=270$, with reduced yet significant variability at $\mathrm{L}_{S}=090$. Finally, the third numerical experiment indicates, as was found in the lower atmosphere by Wilson (1997), that upward propagating waves and tides allow meridional flows to access the thermosphere's winter polar latitudes. This last investigation also indicates that the Hadley circulation responsible for thermospheric winter polar warming originates in the lower atmosphere and extends high into the upper atmosphere. In summary, these new efforts establish a baseline numerical study upon which more comprehensive model-to-data comparisons may be conducted for the Martian thermosphere.

Citation: Bell, J. M., S. W. Bougher, and J. R. Murphy (2007), Vertical dust mixing and the interannual variations in the Mars thermosphere, J. Geophys. Res., 112, E12002, doi:10.1029/2006JE002856.

\section{Introduction and Motivation}

[2] Previous work by Bougher et al. [2006] indicated that the highly coupled nature of the Martian upper and lower atmospheres remains critical to understanding winter polar warming in the lower thermosphere. In particular, they suggested that lower atmospheric dust functions as the dominant driver for the simulated temperature structures. Furthermore, they posited that lower atmospheric dust variations modify a vertically extended interhemispheric

\footnotetext{
${ }^{1}$ Department of Atmospheric, Oceanic, and Space Sciences, University of Michigan, Ann Arbor, Michigan, USA.

${ }^{2}$ Department of Physics and Astronomy, New Mexico State University, Las Cruces, New Mexico, USA.
}

Copyright 2007 by the American Geophysical Union. 0148-0227/07/2006JE002856
Hadley circulation that cools the summer polar thermosphere temperatures while simultaneously warming the winter polar thermosphere temperatures. The simulated thermospheric temperature structures matched the trends found in Mars Odyssey (ODY) and Mars Global Surveyor (MGS) aerobraking data sets. From these simulations, Bougher et al. [2006] hypothesized that a dust driven, summer-to-winter Hadley circulation, resulting from the tight coupling between the upper and lower atmospheres, combines with an in situ Extreme Ultraviolet (EUV) heating driven circulation to produce the observed temperature structures in aerobraking data. However, this previous work focused solely upon reproducing winter polar warming at times that matched available in situ accelerometer data, and it did not attempt a more systematic exploration of the impacts of lower atmospheric dust upon the thermosphere. 
[3] In this work, we characterize the dynamical impact of lower atmospheric dust upon the thermosphere of the coupled Mars General Circulation Model-Mars Thermosphere General Circulation Model (MGCM - MTGCM) through a series of numerical experiments: a dust sensitivity study, an interannual study, and a wave-impact analysis study. In the sensitivity investigation, we focus primarily upon the solstice period of $\mathrm{L}_{S}=090$ and quantify the response of the lower thermosphere's temperature, density, and dynamical structures to variations in lower atmospheric vertical dust mixing altitudes. The interannual study includes both solstice periods $\left(\mathrm{L}_{S}=090\right.$ and $\left.\mathrm{L}_{S}=270\right)$ for three Mars years (24-27) that overlap with three MGS Thermal Emission Spectrometer (TES) mapping years. We utilize the TES database because it provides a nearly continuous lower atmosphere dust climatological database that serves as a natural foundation for modeling a suite of interannual variations in the thermosphere. In the final numerical experiment, we examine the thermosphere's response to variations in its lower boundary coupling with the lower atmosphere at the 1.32- $\mu$ bar pressure level. In essence, this last study measures the variability of the MTGCM's circulation to fluctuations in the amplitude of upward propagating waves and tides transmitted from the lower atmosphere MGCM.

[4] Throughout this work, we highlight the impacts upon the lower thermosphere, spanning the 100-130 km altitude range, which most directly impacts aerobraking missions. Furthermore, it is this altitude range where the winter polar warming features appear most prominently in accelerometer data sets [Keating et al., 1998, 2002, 2003]. To simplify the analysis, we focus on the $120 \mathrm{~km}$ altitude level, which exhibits the average dynamical, thermal, and density variations expected in the lower thermosphere. Also, we specify solar moderate fluxes $\left(\mathrm{F}_{10.7-\mathrm{cm}}=130\right)$ for all simulations, in order to remove any perturbations in solar heating not directly related to the lower atmospheric dust. Although, at $120 \mathrm{~km}$ altitude, the solar EUV heating rates in the MTGCM remain of limited importance relative to the dominant dynamics. Taken together, these limitations remove the possibility of directly comparing simulation results with in situ data. However, these constraints lay the foundation for a detailed theoretical exploration of the fundamental drivers causing the phenomenon of winter polar warming.

\subsection{Interannual and Seasonal Variations: Previous Work}

[5] Although this paper addresses interannual variations in the thermosphere, it builds upon a rich body of literature for both the Martian upper and lower atmospheres [e.g., Angelats $i$ Coll et al., 2004; Bougher et al., 2004, 2006; Forbes et al., 2002; Forget et al., 1996, 1999; Keating et al., 2002; Sante and Crisp, 1993; Theodore et al., 1993; Wilson, 1997, 2002; Withers et al., 2003]. Liu et al. [2003] provides an exhaustive treatment of seasonal and interannual variations in the lower atmosphere. They find, by analyzing MGS TES, Viking Lander, and Mariner 9 data sets, that the northern spring and summer $\left(\mathrm{L}_{S}=000-140\right)$ temperatures remain highly repeatable from year to year. Even after globe-encircling dust storms during the preceding southern summer, the lower atmosphere returns to a nominal state relatively quickly, exhibiting temperature variations of only $1 \mathrm{~K}$ on the nightside and $6 \mathrm{~K}$ on the dayside. Conversely, Liu et al. [2003] find that the opposite seasons, southern spring through southern summer (roughly $\mathrm{L}_{S}=140-360$ ), show a relatively high degree of local variability. These short-term variations arise mostly due to large scale dust-storms, which are observed to occur more frequently during this season. From their work, Liu et al. [2003] maintain that the Martian atmosphere does not possess a significant memory of past events. Instead, the atmosphere displays coherent sequences of repeating dynamical configurations, with departures primarily due to variations in local solar insolation, dust forcing, and waterice interactions.

\subsection{Mars Global Surveyor and Mars Odyssey}

[6] The two satellites, MGS and ODY, have provided a plethora of both in situ and remote data from which to build a climatological database for the Martian lower thermosphere $(100-130 \mathrm{~km})$. Other valuable data sources were available, such as the Viking Landers 1 and 2 (VL1 and VL2) and Mariner 9; however, in this study we focused on the data provided by the MGS and ODY satellites. Both satellites participated in aerobraking maneuvers; the details of these orbital procedures are given by Withers et al. [2003], Withers [2006], and Keating et al. [1998, 2002, 2003]. The analysis of these data sets indicated a strong coupling between the Martian lower and upper atmosphere with three primary components: (1) seasonal and dust driven inflation/contraction of the lower and upper atmospheres, (2) upward propagating migrating and non-migrating tides, and (3) a strong interhemispheric Hadley circulation during solstice conditions in the upper atmosphere.

[7] Significant seasonal variations were discovered during the analysis of both MGS and ODY aerobraking data sets. During MGS Phase 2 aerobraking, lasting from September 1998 to February 1999, accelerometer sampling occurred during the approach to southern winter solstice, $\mathrm{L}_{S}=030-090$. The satellite possessed a nearly polar orbit with periapsis approaching the southern pole. As the satellite tracked from equatorial to polar latitudes, accelerometerderived temperatures in the lower thermosphere (altitudes spanning $100-130 \mathrm{~km}$ ) increased from $100 \mathrm{~K}$ up to a maximum of $110 \mathrm{~K}$, subsequently declining to polar night values of $90 \mathrm{~K}$ to $100 \mathrm{~K}$. Similarly, Odyssey possessed a near-polar orbit with periapsis approaching the northern pole near southern summer solstice, $\mathrm{L}_{S}=250-300$. In this instance, the ODY accelerometer found strong polar warming features, rising from $100 \mathrm{~K}$ at mid latitudes and peaking at $160 \mathrm{~K}$ at the northern winter polar night [Keating et al., 2003]. Bougher et al. [2006] provides more details on these seasonal variations in these winter polar warming structures in the lower thermosphere.

[8] In short, these two satellites provide a wealth of overlapping data that contribute to a growing climatological database for the Martian lower thermosphere. Despite the usefulness of these data sets, they still possess significant shortcomings, such as: limited local time and latitude sampling, and sporadic sampling throughout the solar cycle. However, the TES lower atmospheric IR opacity represents the single most important data set for the present study. Using these IR opacity maps, derived dust distributions in 


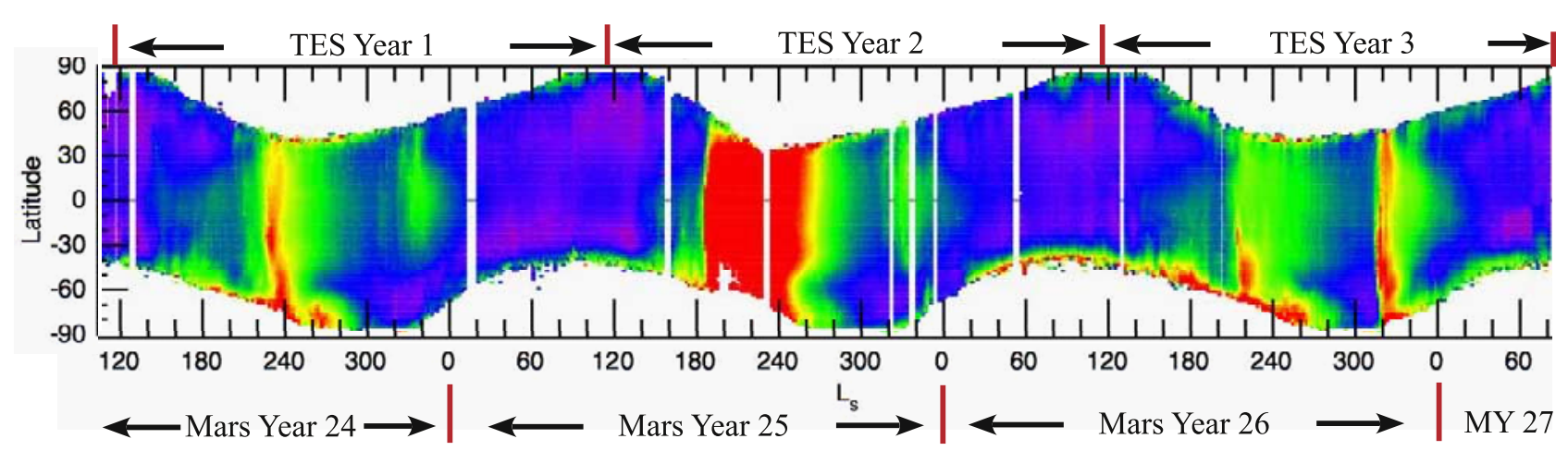

Figure 1. Martian lower atmosphere dust opacities (unitless) as a function of latitude for three consecutive TES years. Note that TES years do not overlap directly with conventional Mars Years, which are shown below the panel. All opacities are zonally averaged quantities. By convention, the purple is $\tau=$ 0.0, while the red is $\tau=0.5$. This figure was adapted from Smith [2006].

latitude, longitude, and altitude are generated for use in the lower atmosphere MGCM.

\subsection{Thermal Emission Spectrometer}

[9] The TES instrument on board MGS provides nearly continuous IR optical depth measurements, yielding maps for over three consecutive years [Liu et al., 2003; Christensen et al., 2001; Smith, 2004]. These maps span most of the Martian globe. However, the winter polar regions pose a problem, due to their low luminosity at IR wavelengths. Further, this longwave radiation represents a good proxy for mixing ratio variations of micron-size dust particles $(1-$ $10 \mu \mathrm{m})$.

[10] By cataloguing the data collected by TES over its lifetime, a suspended dust climatological database emerges that provides comprehensive spatial and temporal coverage for three consecutive Martian years. Figure 1 illustrates column-integrated dust opacity distributions (zonally averaged) as a function of latitude and season over three Martian years. In this work, we utilize the TES observed opacities to specify the spatial distribution of suspended dust in the lower atmosphere MGCM, and evaluate their impacts on the global circulation and structure of the upper atmosphere MTGCM.

[11] At polar latitudes, where surface temperatures are less than $220 \mathrm{~K}$ and TES IR opacity maps are not readily available, we extrapolated the available IR opacity data in the lower atmospheric MGCM to ensure non-zero dust opacities over the entire Martian globe. To accomplish this, we simply reduced the TES opacity at the highest available latitude by a factor of 0.80 for each latitude grid cell in the MGCM poleward of the data. For instance, if the last available (i.e., highest latitude) TES opacity data point possessed a value of $\tau=1.0$ at $50^{\circ} \mathrm{N}$, then the extrapolated dust opacity in the adjacent grid cell at $55^{\circ} \mathrm{N}$ would be $\tau=$ 0.80 . Further, the grid cell at $60^{\circ} \mathrm{N}$ would have $\tau=0.64$ and so on to the pole. This method allowed us to generate continuous lower atmospheric dust opacities over the entire Martian globe during all of our TES Year simulations.

[12] In the context of this work, two measures of time remained important. First, the TES Year time stamp was keyed to the beginning of the MGS mapping phase, which began in March 1999. This first TES mapping year, dubbed TES Year 1, began at $\mathrm{L}_{S}=104$ of Mars Year 24 and data collection continued until the end of its mapping mission, which was approximately $\mathrm{L}_{S}=081$ during Mars Year 27 . Although $\mathrm{L}_{S}=081$ marks the end of the TES mapping phase as it is defined in this paper, the instrument still provided data intermittently from that date until $\mathrm{L}_{S}=160$.

[13] Figure 1 illustrates the relationship between the Mars Years and TES Mapping Years. It should be noted that some controversy surrounds the assignment of Mars Years [Suran, 1997; Gangale and Dudley-Rowley, 2005]. In this paper, we adopt the timekeeping standard put forth by Clancy et al. [2000] and Smith [2004], which designates $\mathrm{L}_{S}=000$ of Mars Year 0 on 11 April 1955. These lower atmospheric dust distributions are incorporated into the lower atmosphere MGCM, where thermal structures, dynamics, and chemistry are self-consistently calculated. Then, key outputs-Temperature (T), Zonal Winds (U), Meridional Winds (V), and Geopotential Height $(\Phi)$ - are produced at each 2-minute time step at the 1.32- $\mu$ bar level. These outputs are then interpolated to the Mars Thermosphere General Circulation Model (MTGCM) grid at each time step. In the next section, the details of both models are discussed.

\section{Coupled Model (MGCM-MTGCM)}

[14] The MTGCM itself is a finite difference primitive equation model that self-consistently solves for timedependent neutral temperatures, neutral-ion densities, and three component neutral winds over the globe [Bougher et al., 1999a, 1999b, 2000, 2004, 2006]. Prognostic equations for the major neutral species $\left(\mathrm{CO}_{2}, \mathrm{CO}, \mathrm{N}_{2}\right.$, and $\left.\mathrm{O}\right)$, selected minor neutral species ( $\mathrm{Ar}, \mathrm{He}, \mathrm{NO}, \mathrm{N}\left({ }^{4} \mathrm{~S}\right)$, and $\left.\mathrm{O}_{2}\right)$, and several photochemically produced ions (e.g., $\mathrm{O}_{2}^{+}, \mathrm{CO}_{2}^{+}, \mathrm{O}^{+}$, and $\mathrm{NO}^{+}$below $180 \mathrm{~km}$ ) are included. All fields are calculated on 33 pressure levels above $1.32-\mu \mathrm{bar}$, corresponding to altitudes from roughly 70 to $300 \mathrm{~km}$ (at solar maximum conditions), with a $5^{\circ}$ resolution in latitude and longitude. The vertical coordinate is log pressure, with a vertical spacing of 0.5 scale heights. Key adjustable parameters which can be varied for individual MTGCM cases 
include the $\mathrm{F}_{10.7-\mathrm{cm}}$ index (solar EUV/UV flux variation), the heliocentric distance and solar declination corresponding to Mars seasons. The MTGCM is a modified version of the National Center for Atmospheric Research (NCAR) Thermospheric-Ionospheric-Energetics General Circulation Model (TIE-GCM) [Roble et al., 1988]. Detailed discussion of this modification is given in Bougher et al. [2000]. Currently, a fast non-Local Thermodynamic Equilibrium (NLTE) 15-micron cooling scheme is implemented in the MTGCM, along with corresponding near-IR heating rates Bougher et al. [2006]. These improvements are based upon recent detailed one-dimensional (1-D) NLTE model calculations for the Mars upper atmosphere [e.g., López-Valverde et al., 1998].

[15] The MTGCM is currently driven from below by the NASA Ames Mars General Circulation Model (MGCM) code [Haberle et al., 1999] at the 1.32- $\mu$ bar level (near 60$80 \mathrm{~km}$ ). This coupling allows both the migrating and nonmigrating tides to cross the MTGCM lower boundary and the effects of the expansion and contraction of the Mars lower atmosphere to extend to the thermosphere. The entire atmospheric response to simulated dust storms can also be monitored using these coupled models. Key prognostic variables are passed upward from the MGCM to the MTGCM at the 1.32- $\mu$ bar level at every MTGCM grid point: Temperature (T), zonal (U) and meridional (V) winds, and geopotential height $(Z)$. The continuity equation is solved to provide consistent vertical velocities (W) across this 1.32- $\mu$ bar lower boundary. Two-dimensional (2-D) interpolation is applied to construct MGCM fields at the $1.32-\mu$ bar level to match the $5^{\circ} \times 5^{\circ}$ MTGCM grid. These two climate models are each run with a 2-minute time step, with the MGCM exchanging fields with the MTGCM at this frequency. Eight Sol (the Martian Day) runs are conducted for various Mars seasonal and solar cycle conditions. This coupled configuration has been previously validated using an assortment of spacecraft observations, including MGS Phase 1 and 2 and ODY aerobraking data sets [Bougher et al., 1999b, 2000, 2004, 2006]. Additionally, no downward coupling is presently activated between the MGCM and the MTGCM. However, the impacts of the lower atmosphere's dynamics upon the upper atmosphere remain the dominant concern of this paper.

[16] At present, a simple photochemical ionosphere is formulated for the MTGCM including, e.g., $\mathrm{O}_{2}^{+}, \mathrm{CO}_{2}^{+}, \mathrm{O}^{+}$, and $\mathrm{NO}^{+}$below $180 \mathrm{~km}$. Key ion-neutral reactions and rates are taken from Fox and Sung [2001]; empirical electron and ion temperatures are adapted from the Viking mission. The ionization rates required for the production rates are calculated self-consistently, making use of specified solar EUV fluxes. Photoelectron contributions to these ionization rates are parameterized within the MTGCM code.

[17] The NASA Ames MGCM is a primitive equation, grid-point numerical model of the Martian atmosphere. It contains a variety of numerical parameterizations for the treatment of such physical processes as radiative transfer (solar absorption and infrared absorption and emission by gaseous $\mathrm{CO}_{2}$ and suspended dust), atmospheric/surface interactions (transfer of momentum and sensible heat), condensation/sublimation of carbon dioxide (and the concurrent changes in atmospheric mass), and imposed flow deceleration near the model top (for both physical and numerical reasons). The model is thoroughly discussed by Pollack et al. [1990] and Haberle et al. [1999].

\section{Specifying Lower Atmospheric Dust in the MTGCM-MGCM: Two Approaches}

[18] Previous studies of lower atmospheric dust in Mars atmosphere have focused on reproducing observed dust vertical profiles through numerical and theoretical modeling [Conrath, 1975; Murphy et al., 1990, 1993]. These studies explored the effects of particle shape, particle size, and atmospheric circulation patterns on simulated dust vertical mixing profiles and on the physics underlying the dustatmosphere feedback system.

[19] For the current research, the numerical methods for describing the lower atmospheric dust mixing remained critical. The dust in the lower atmosphere was specified as a function of latitude, longitude, and altitude in the lower atmosphere MGCM. The total integrated IR dust opacity was specified at the $6.1-\mathrm{mb}$ pressure level. The resulting vertical dust mixing profiles followed directly from the formalism of Conrath [1975], which can be summarized by the following:

$$
\nu=\frac{t_{D}}{t_{s}(0)},
$$

where $t_{s}(0)$ is the dust particles' characteristic settling time at $z=0$ and $t_{D}$ is the vertical diffusion time of the dust given by

$$
t_{D}=\frac{H^{2}}{K}
$$

[20] Here, $H$ is the local atmospheric scale height (roughly $8-10 \mathrm{~km}$ in the lower atmosphere) and $K$ is the local eddy diffusion coefficient. Finally, these $\nu$ parameters are then used in the following vertical mixing profile:

$$
q(z, \phi, \theta)=q(0, \phi, \theta) e^{\left(\nu\left[1-e^{\left(\frac{z}{H}\right)}\right]\right)}
$$

[21] Sample vertical profiles, corresponding to three $\nu$ values, are illustrated in Figure 2. In Figure 2, the line plots represent the average variation of dust mixing ratio as a function of altitude, and they are meant only as an approximation to the actual dust mixing profiles employed in this study. The Conrath profile describes the vertical dust mixing ratio above a specific point, defined in Figure 2 as $q(0, \phi, \theta)$. We define this base level as the $6.1-\mathrm{mb}$ pressure level, below which the lower atmospheric dust is assumed to be well-mixed to the surface, and above which the lower atmosphere dust is assumed to fall off with the exponential character of equation (3).

[22] For clarification on the physical implications of the three Conrath parameters shown in Figure 2, the three values of $\nu=0.3,0.03$, and 0.005 correspond to uniform local eddy diffusion coefficients of $10^{5}, 6 \times 10^{5}$, and $5 \times$ $10^{6} \mathrm{~cm}^{2} / \mathrm{s}$, respectively. Furthermore, it should be noted that these eddy diffusion coefficients are less than the values utilized by Conrath [1975] because this previous research does not explicitly account for dynamical dust lifting as we do in the current work. Next, the latitudinal and longitudinal variations in the MGCM lower atmospheric dust levels 


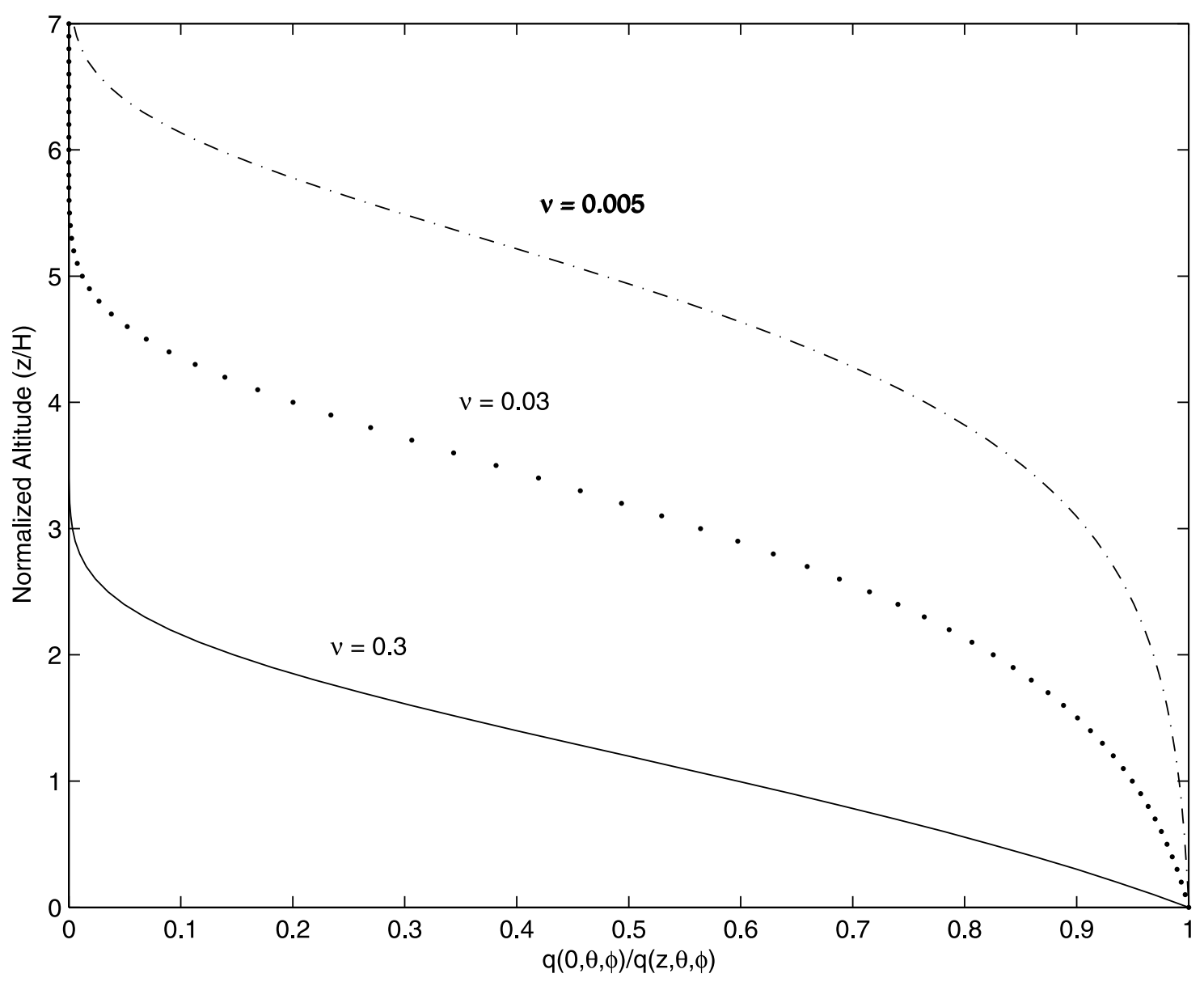

Figure 2. Illustration of Conrath vertical dust mixing profiles as a function of altitude above a given reference level. The zero-altitude level in this work is assumed to be the $6.1-\mathrm{mb}$ pressure level. Note the connection between the $\nu$ value and the effective dust mixing altitudes.

comprise the major distinctions between the first two studies employed in this work and are further discussed below.

\subsection{Dust Profiles for the Sensitivity Study}

[23] This numerical experiment seeks to quantify the impacts of the lower atmosphere vertical dust mixing on the MTGCM's temperatures, densities, and circulation. Because of this, we conduct controlled numerical experiments with the lower atmospheric dust specifications, employing uniform dust distributions at the $6.1-\mathrm{mb}$ pressure level. In other words, the value of $q(0, \phi, \theta)$ of Figure 2 is held constant at a preset value, while we vary the $\nu$ parameter, which specifies the rate of exponential fall off in the lower atmospheric dust's vertical mixing ratio. This globally symmetric dust distribution isolates the impact of vertical mixing of the dust on the MTGCM lower thermosphere. However, as shown in Figure 1, a globally symmetric dust distribution remains inappropriate for most of the Martian year. In order to explore how non-uniform dust distributions impact the MTGCM simulations, we turn to the next phase of the present work.

\subsection{Dust Profiles for the Interannual Study}

[24] For the interannual investigation, we derive the lower atmospheric dust distribution, $q(0, \phi, \theta)$, from the TES IR opacity data, which is shown zonally averaged in Figure 1 as a function of time. However, for this experiment, the vertical mixing now varies as a function of the lower atmospheric integrated dust opacity. Essentially, the higher the total opacity in the TES data, the more deeply the dust is assumed to mix vertically in Mars' lower atmosphere. For example, the purple regions in Figure 1 correspond to a total opacity of near 0.0 , which indicates that very little dust existed in the atmosphere and that the dust would not mix to high altitudes. By contrast, the red regions indicate total opacity of 0.5 , which results in both a much larger amount of dust in the lower atmosphere and mixing the dust to much higher altitudes. Thus the $\nu$ parameter, which specifies the rate of exponential fall off in the lower atmospheric dust's vertical mixing ratio, varies as a function of $\theta$ and $\phi$ that is derived directly from the TES IR opacity maps in Figure 1.

\section{Sensitivity of the MTGCM Lower Thermosphere to Vertical Dust Mixing}

[25] This sensitivity study isolates the impacts of the lower atmospheric dust parameters on the MTGCM lower thermosphere by systematically varying (1) vertical dust mixing altitudes, (2) the total amount of dust in a column or optical depth, $\tau$, between 0.3 and 1.0, and (3) seasonal 

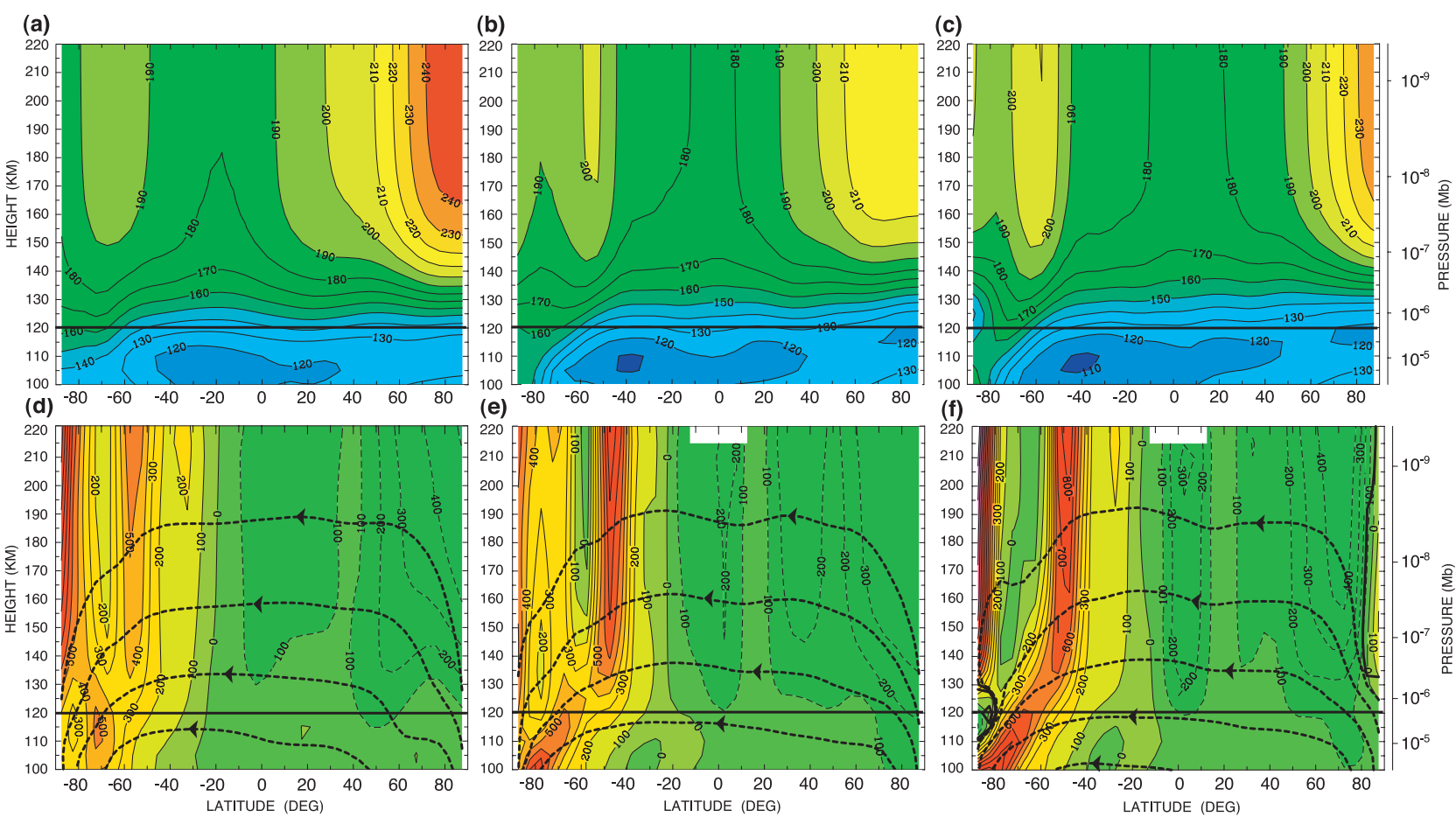

Figure 3. Zonal average neutral temperatures are shown in Figures $3 a-3 c$, while adiabatic heating (positive contours) and cooling (negative contours) are shown in Figures $3 \mathrm{~d}-3 \mathrm{f}$, for the various lower atmospheric vertical dust mixing profiles as a function of both altitude (vertical axis) and latitude (horizontal axis). The season is held constant at $\mathrm{L}_{S}=090$ for all simulations, as is the total integrated lower atmospheric dust opacity, $\tau=0.3$, and solar flux at $\mathrm{F}_{10.7-\mathrm{cm}}=130$. The black horizontal line in all plots represents $120 \mathrm{~km}$ altitude level. Neutral temperatures (in K) are depicted for the various lower atmospheric dust mixing heights: (a) the lowest $\nu=0.3$, (b) medium $\nu=0.03$, and (c) highest $\nu=0.005$. Similarly, the adiabatic heating and cooling contours (in K/day) and the overlain meridional stream functions are depicted for the various lower atmospheric dust mixing heights: (d) the lowest $\nu=0.3$, (e) medium $\nu=0.03$, and (f) highest $\nu=0.005$. The neutral stream functions are dimensionless and are indicative of the zonal averaged flow directions. The respective maximum meridional winds at $120 \mathrm{~km}$ are (by convention, negative values are southward, while positive values are northward) (d) $-100 \mathrm{~m} / \mathrm{s}$, (e) $-120 \mathrm{~m} / \mathrm{s}$, and (f) $-140 \mathrm{~m} / \mathrm{s}$.

variations at $\mathrm{L}_{S}=090$ and 270 . In this experiment, we investigate each variable's impact independent of the others, through a series of tests detailed below.

\subsection{Varying the Vertical Dust Mixing Profiles}

[26] Figures 3 and 4 illustrate the response of the MTGCM lower thermosphere to variations in the vertical dust mixing height. In both figures, the season, total integrated dust opacity at $6.1-\mathrm{mb}$, and solar fluxes are held constant at $\mathrm{L}_{S}=090, \tau=0.3$, and $\mathrm{F}_{10.7-\mathrm{cm}}=130.0$ (Solar Moderate), respectively. All plots contain zonal mean quantities, allowing us to integrate over both local time and topograhically forced variations. Additionally, we use $120 \mathrm{~km}$ altitude, denoted by the horizontal black lines in these figures, as a proxy for the overall response of the lower thermosphere $(100-130 \mathrm{~km})$.

\subsubsection{Response of the MTGCM Temperatures}

[27] The temperatures for the low $(\nu=0.3)$, medium $(\nu=$ $0.03)$, and high $(\nu=0.005)$ dust mixing profiles are shown in Figures 3a, 3b, and 3c, respectively. Similarly, Figures 3d, $3 \mathrm{e}$, and $3 \mathrm{f}$ contain the corresponding adiabatic heating and cooling rates (colored contours) with overlying zonal mean stream functions (black dotted lines). Moving from Figure $3 \mathrm{a}$ to Figure $3 \mathrm{c}$, the lower atmospheric dust is mixed from the lowest altitude to the highest altitude. Furthermore, the maximum meridional velocities at $120 \mathrm{~km}$ are indicated in the figure caption for each of the vertical mixing heights in $\mathrm{m} / \mathrm{s}$.

[28] Focusing on $120 \mathrm{~km}$ altitude in Figure 3a, temperatures near the equator begin at $140 \mathrm{~K}$. Moving toward the southern winter polar region, the temperatures rise to $160 \mathrm{~K}$ at $70^{\circ} \mathrm{S}$ and then remain steady into the pole. This results in a minimum-to-maximum polar warming feature of $\Delta \mathrm{T}=$ $20 \mathrm{~K}$. Figure $3 \mathrm{~b}$, following the same trajectory, shows a warming from nearly $130 \mathrm{~K}$ at the equator to just over $160 \mathrm{~K}$ near $80^{\circ} \mathrm{S}$, corresponding to a $\Delta \mathrm{T}=30 \mathrm{~K}$. Lastly Figure $3 \mathrm{c}$, at $120 \mathrm{~km}$, depicts a warming from $128 \mathrm{~K}$ at the equator to nearly $165 \mathrm{~K}$ near $75^{\circ} \mathrm{S}$ latitude, followed by a steep cooling into the pole. This last figure possesses a temperature change of $\Delta \mathrm{T}=37 \mathrm{~K}$. Thus, in moving from Figure 3a to Figure $3 \mathrm{c}$ the MTGCM temperatures exhibit a systematically larger winter polar warming feature, as illustrated by 

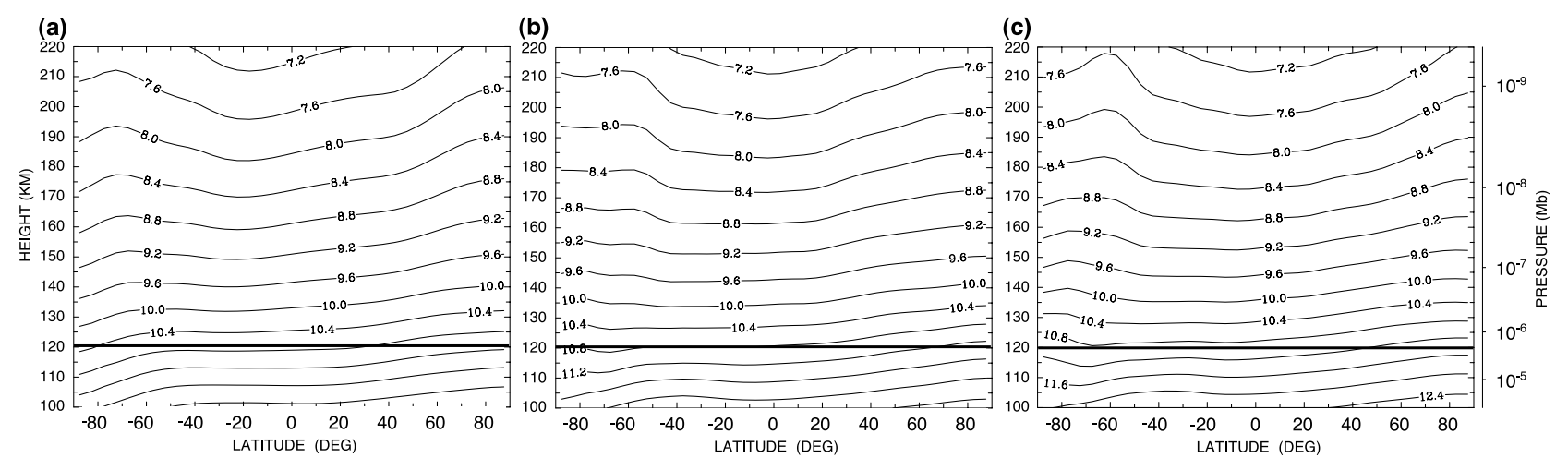

Figure 4. Zonal average $\log _{10} \mathrm{~cm}^{-3}$ neutral densities (in Figures $4 \mathrm{a}-4 \mathrm{c}$ ) for the various lower atmospheric vertical dust mixing profiles as a function of both altitude (vertical axis) and latitude (horizontal axis). The season is held constant at $\mathrm{L}_{S}=090$ for all simulations, as is the total integrated dust opacity, $\tau=0.3$, and solar flux $\mathrm{F}_{10.7-\mathrm{cm}}=130$. The black horizontal line in all plots represents $120 \mathrm{~km}$ altitude level. Neutral densities (in $\log _{10} \mathrm{~cm}^{-3}$ ) are depicted for the various lower atmospheric dust mixing heights: (a) the lowest $\nu=0.3$, (b) medium $\nu=0.03$, and (c) highest $\nu=0.005$.

the $\Delta \mathrm{T}$ 's found at $120 \mathrm{~km}$. In other words, as the lower atmospheric dust vertical mixing height increases, the winter polar warming feature at $120 \mathrm{~km}$ simultaneously increases. The winter polar warming features for each dust mixing height are contained in Table 1.

[29] At $120 \mathrm{~km}$ altitude in the equatorial and summer latitudes, the lower thermosphere exhibits a net cooling effect, as dust is mixed higher in the lower atmosphere. The equatorial temperatures of Figures $3 \mathrm{a}, 3 \mathrm{~b}$, and $3 \mathrm{c}$ are $140 \mathrm{~K}$, $130 \mathrm{~K}$, and $128 \mathrm{~K}$, respectively. Similarly, the minimum temperature at $120 \mathrm{~km}$, which occurs near the summer pole, for each panel is likewise $135 \mathrm{~K}, 120 \mathrm{~K}$, and $117 \mathrm{~K}$. Thus the summer polar thermosphere exhibits a summer polar cooling that is amplified as the lower atmospheric vertical dust mixing increases. This simultaneous cooling of the summer polar thermosphere while the winter polar thermosphere is warmed indicates that energy is being transported from the summer to the winter hemisphere. We explore this transport mechanism further in the following section.

4.1.2. MTGCM Adiabatic Heating and Cooling Rates

[30] There are five primary drivers for thermal structure in the Mars Thermosphere General Circulation Model (MTGCM): thermal conduction, $\mathrm{CO}_{2} 15-\mu \mathrm{m}$ cooling, solar heating, hydrodynamic advection, and adiabatic heating/ cooling. Of these five drivers, adiabatic heating (due to convergence of meridional and vertical flows) and cooling (due to divergence of meridional and vertical flows), emerges as the single most significant contributor to the variations in the lower thermosphere structures found in this study. The other source terms possess comparatively smaller amplitudes in the MTGCM at these altitudes. Consequently, we focus the discussion on the adiabatic heating and cooling, which are shown in Figures $3 d-3 f$.

[31] From Figures $3 d-3 f$, a trend similar to that found in the winter polar temperature structures appears in the adiabatic term as well. First, moving from Figure $3 \mathrm{~d}$ to Figure 3f, the adiabatic heating in the winter polar thermosphere intensifies at $120 \mathrm{~km}$ as the lower atmospheric vertical dust mixing height is increased. In Figure 3d, the peak adiabatic heating at $120 \mathrm{~km}$ is $400-450 \mathrm{~K} /$ day, whereas in Figures $3 \mathrm{e}$ and $3 \mathrm{f}$ the heating in the lower thermosphere increases to $500 \mathrm{~K} /$ day and $600 \mathrm{~K} /$ day, respectively. This intensification in the adiabatic heating term parallels the resulting winter polar thermal structures found in Figures 3a-3c.

[32] In the opposite hemisphere, the northern summer latitudes, adiabatic cooling rates do not systematically intensify as the lower atmospheric dust is mixed to higher altitudes, moving from Figures $3 \mathrm{~d}-3 \mathrm{f}$. At $120 \mathrm{~km}$, the maximum adiabatic cooling for Figures $3 \mathrm{~d}, 3 \mathrm{e}$, and $3 \mathrm{f}$ is $-100 \mathrm{~K} /$ day, $-200 \mathrm{~K} /$ day, and $-150 \mathrm{~K} /$ day. This trend in adiabatic cooling contrasts with the clearly increasing adiabatic heating rates in the winter polar latitudes with an increasing vertical dust mixing height in the lower atmosphere. However, inspection of these same panels suggests an explanation for this difference.

[33] First, Figures $3 \mathrm{~d}-3 \mathrm{f}$ demonstrate that the adiabatic cooling extends over most, if not all, of the northern hemisphere. Simultaneously, the peak polar warming features of these same plots remain confined to a small subset of winter polar latitudes. Therefore any increase in the adiabatic cooling of the summer latitudes distributes itself across a larger spatial extent in the northern hemisphere. Thus the impact of increasing the lower atmosphere vertical dust mixing height should not manifest itself in cooling the summer hemisphere as acutely as it does in warming the winter pole. This asymmetric adiabatic impact reveals itself in the temperature plots of Figures $3 a-3 c$. However, despite the less intense impact of the adiabatic cooling upon the summer thermosphere, the results suggest that the summer lower thermosphere temperatures do systematically decrease, as the dust is mixed higher in the lower atmosphere.

Table 1. Polar Warming Features in Kelvin for Sensitivity Study

\begin{tabular}{ccccc}
\hline Season & $\begin{array}{c}\text { Total } \\
\text { Opacity }\end{array}$ & $\begin{array}{c}\nu=0.3 \\
\text { (Low) }\end{array}$ & $\begin{array}{c}\nu=0.03 \\
\text { (Medium) }\end{array}$ & $\begin{array}{c}\nu=0.005 \\
\text { (High) }\end{array}$ \\
\hline $\mathrm{L}_{S}=090$ & $\tau=0.3$ & $\Delta \mathrm{T}=20 \mathrm{~K}$ & $\Delta \mathrm{T}=30 \mathrm{~K}$ & $\Delta \mathrm{T}=37 \mathrm{~K}$ \\
$\mathrm{~L}_{S}=090$ & $\tau=1.0$ & - & $\Delta \mathrm{T}=40 \mathrm{~K}$ & - \\
$\mathrm{L}_{S}=270$ & $\tau=1.0$ & - & $\Delta \mathrm{T}=73 \mathrm{~K}$ & - \\
\hline
\end{tabular}


[34] Although intensifications in the adiabatic heating and cooling rates strongly correlate with winter polar warming and summer hemisphere cooling, respectively, the meridional and vertical flows in the thermosphere emerge as the ultimate drivers for this system. In order to illustrate the zonal average circulation and its impact on the thermosphere, stream functions for each lower atmospheric dust mixing level have been plotted in Figures $3 \mathrm{~d}-3 \mathrm{f}$. These stream functions, although dimensionless, indicate the direction of the zonally averaged meridional flows in the thermosphere. As can be seen in Figures $3 d-3 f$, the stream function through all three mixing levels shows a consistently well developed summer-to-winter Hadley circulation that produces the adiabatic heating and cooling structures of the same panels. Further, from the caption of this same figure, note how the maximum meridional circulation velocities at $120 \mathrm{~km}$ respond to an increase with the vertical dust mixing height in the lower atmosphere, where they rise from $-100 \mathrm{~m} / \mathrm{s}$ in Figure $3 \mathrm{~d}$ up to $-120 \mathrm{~m} / \mathrm{s}$ in Figure $3 \mathrm{e}$ and finally $-140 \mathrm{~m} / \mathrm{s}$ in Figure $3 \mathrm{f}$. Thus enhancements in the adiabatic heating and cooling rates are most likely the direct result of this interhemispheric Hadley circulation. Furthermore, the resulting heating and cooling rates, in turn, produce the observed temperature variations seen in the lower thermosphere.

\subsubsection{Response of the MTGCM Neutral Densities}

[35] In a manner similar to Figure 3, Figure 4 depicts the response of the logarithm of the MTGCM neutral densities to variations in the lower atmosphere vertical dust mixing. Again focusing on $120 \mathrm{~km}$ as a proxy for the lower thermosphere, we find that, in general, winter polar densities are enhanced as the lower atmospheric dust vertical mixing is increased. In Figure $4 \mathrm{a}$, moving from the equator to the winter pole, the densities begin at $5.0 \times 10^{10} \mathrm{~cm}^{-3}$ and remain steady until $70^{\circ} \mathrm{S}$, subsequently dropping to $2.0 \times 10^{10} \mathrm{~cm}^{-3}$ in the winter pole. This corresponds to polar densities $40.0 \%$ of the equatorial densities. Similarly, in Figure $4 \mathrm{~b}$ the equatorial densities are nearly $6.3 \times$ $10^{10} \mathrm{~cm}^{-3}$ and remain steady even into the polar regions, dropping to $5.0 \times 10^{10} \mathrm{~cm}^{-3}$, which results in polar densities $79.4 \%$ of equatorial densities. Finally, in Figure $4 c$, the neutral densities at $120 \mathrm{~km}$ begin at $1.0 \times 10^{11} \mathrm{~cm}^{-3}$ near the equator and again remain steady, until increasing to $1.3 \times 10^{11} \mathrm{~cm}^{-3}$ at the southern pole, implying polar densities $130 \%$ of the equatorial densities. Ultimately, as lower atmospheric vertical dust mixing increases, a simultaneous increase in winter polar neutral densities occurs at $120 \mathrm{~km}$.

[36] In order to illustrate the significance of these density enhancements near the winter pole, one can compare these variations with those at the equator. The densities at the equator rise from $5.0 \times 10^{10} \mathrm{~cm}^{-3}$ in Figure $4 \mathrm{a}$ to $1.0 \times$ $10^{11} \mathrm{~cm}^{-3}$ in Figure $4 \mathrm{c}$, corresponding to a low-latitude enhancement of $100 \%$ in neutral densities. By contrast, the winter polar neutral densities increase from $2.0 \times 10^{10}$ $\mathrm{cm}^{-3}$ in Figure $4 \mathrm{a}$ to $1.3 \times 10^{11} \mathrm{~cm}^{-3}$ in Figure $4 \mathrm{c}$, corresponding to a increase of $650 \%$. Thus, as the lower atmospheric dust levels increase from the lowest mixing level to the highest, the winter polar regions are experiencing a neutral density enhancement of roughly 550\% more than that experienced at the equator. The equatorial density increases should quantify the impacts of the lower atmos- phere's inflation in response to increased lower atmospheric dust. However, this simple physics cannot explain the significantly higher density perturbations experienced in the thermosphere's winter polar regions. Instead, these simulations suggest that the interhemispherical Hadley circulation dominating the neutral temperatures in the winter polar regions also appears to modify the winter polar thermosphere's neutral density structures significantly.

\subsection{Response of the MTGCM to Total Integrated Dust Opacities}

[37] Next, we illustrate the MTGCM's response to changing the total integrated dust opacity at $6.1-\mathrm{mb}$ from $\tau=0.3$ to 1.0, while holding the season constant at $\mathrm{L}_{S}=090, \nu=$ 0.03 , and $F_{10.7-\mathrm{cm}}=130.0$ (Solar Moderate). The results of this change are illustrated in Figures 5a and 5c. These panels are directly comparable to Figures $3 \mathrm{~b}$ and $3 \mathrm{e}$. Again picking out the $120 \mathrm{~km}$ altitude and moving from the equator to the southern winter polar atmosphere, we find that the temperatures begin at $130 \mathrm{~K}$ and achieve a maximum of $170 \mathrm{~K}$ at the winter pole $(\Delta \mathrm{T}=40 \mathrm{~K})$. This change in temperature represents an increase over the corresponding winter polar warming seen in Figure $3 \mathrm{~b}$ by $10 \mathrm{~K}(33 \%)$. Furthermore, the peak temperature has migrated from $80^{\circ} \mathrm{S}$ in the previous figure to the winter pole in Figure 5 .

[38] Comparing Figure 5c and Figure 3e, one finds that the adiabatic heating and cooling term is greatly modified. First, adiabatic heating is enhanced in the winter pole at $120 \mathrm{~km}$ in Figure $5 \mathrm{~b}(700 \mathrm{~K} /$ day peak heating at $120 \mathrm{~km})$ over the corresponding adiabatic heating found in Figure $3 \mathrm{e}$ $(500 \mathrm{~K} /$ day peak heating at $120 \mathrm{~km})$. This increase in adiabatic heating is not solely the result of an intensified meridional circulation, since Figures $5 \mathrm{~b}$ and $3 \mathrm{e}$ both possess peak meridional winds of -110 to $-120 \mathrm{~m} / \mathrm{s}$. Rather, Figure $5 \mathrm{~b}$ exhibits a much larger vertical wind component of $-1.5 \mathrm{~m} / \mathrm{s}$ (downward) compared with the earlier simulation's vertical wind speed of $-1.0 \mathrm{~m} / \mathrm{s}$ (downward). Thus we again find that an intensification of the Hadley circulation, resulting in an increased adiabatic heating in the winter polar thermosphere, ultimately produces the enhanced polar warming features of Figure $5 \mathrm{a}$.

[39] From this comparison, it is evident that an increased integrated dust opacity in the lower atmosphere, while keeping all other variables constant, results in an increase in the polar warming features simulated in the Martian lower atmosphere. Although, only one instance of this is shown for the $\mathrm{L}_{S}=090$ season, moderate solar fluxes, and at medium vertical dust mixing height $(\nu=0.03)$, this same trend still holds in general for the MTGCM's response to an increase of the total integrated lower atmospheric dust opacity. For brevity, we include only this single case to illustrate this more universal trend.

\subsection{Response of the MTGCM to Seasonal Variations}

[40] Figures $5 \mathrm{~b}$ and $5 \mathrm{~d}$ illustrate the impact of changing seasons from $\mathrm{L}_{S}=090$ to $\mathrm{L}_{S}=270$. Figures $5 \mathrm{~b}$ and $5 \mathrm{~d}$ should be directly compared with Figures $5 \mathrm{a}$ and $5 \mathrm{c}$, as both possess (1) a uniform dust distribution with total integrated dust opacity $(\tau=1.0)$ at the $6.1-\mathrm{mb}$ pressure level, (2) a medium mixing height $(\nu=0.03)$, and (3) moderate solar fluxes. Thus the primary difference between these two 


\section{(a)}
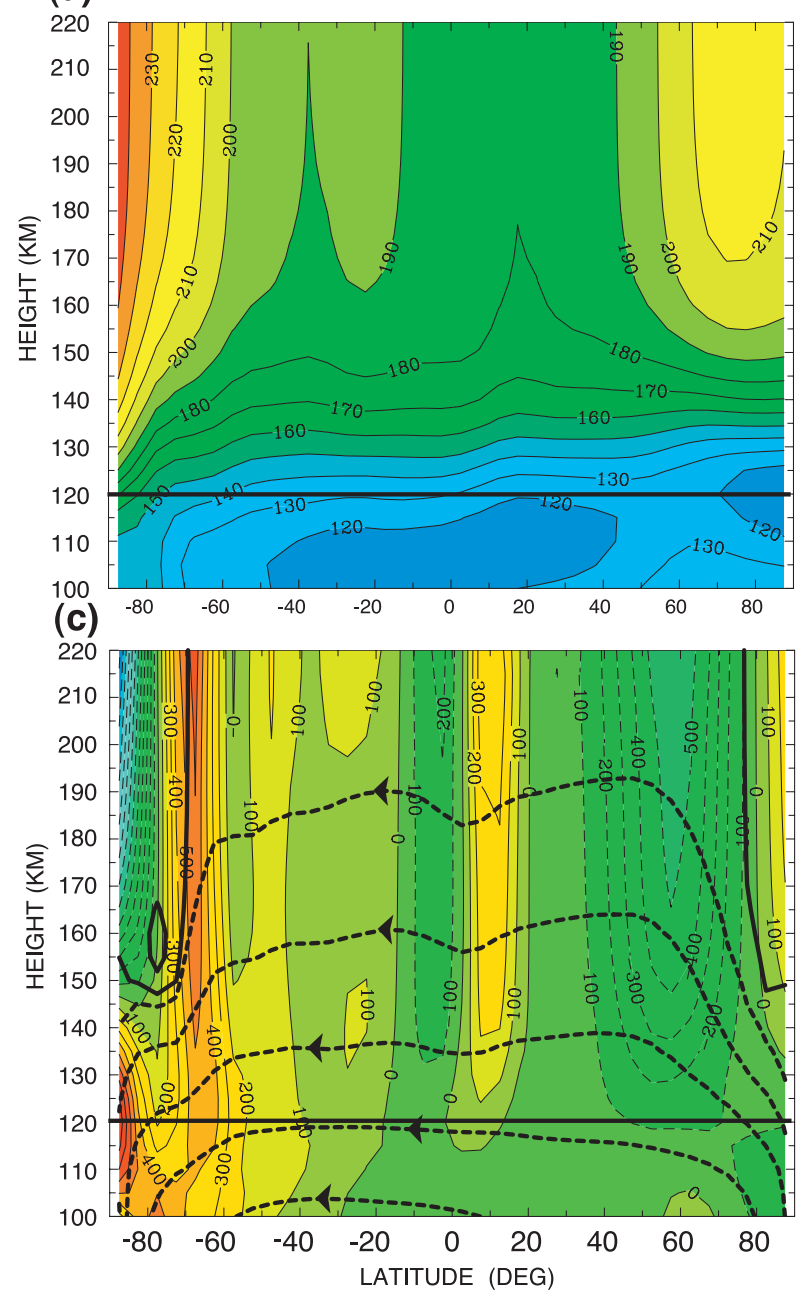

\section{(b)}

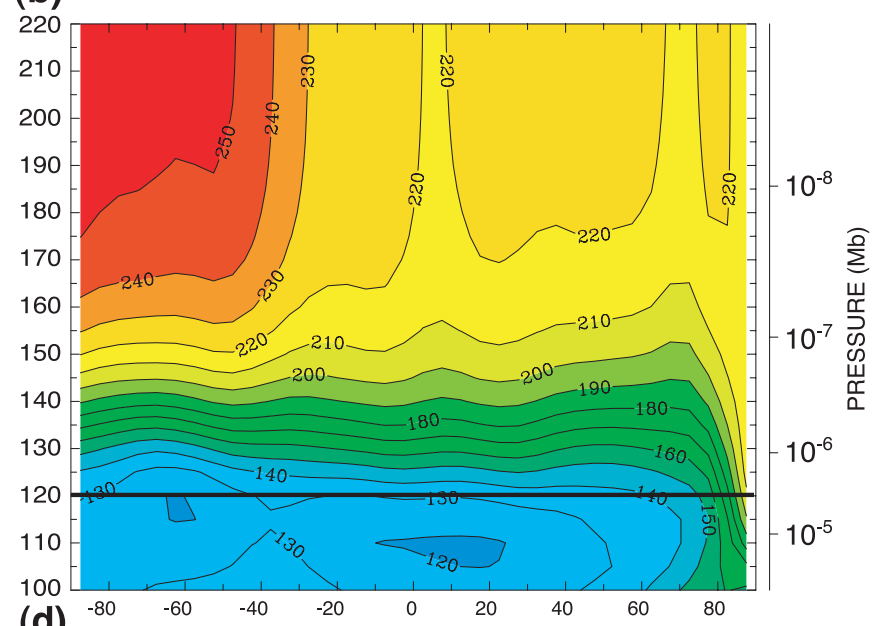

(d)

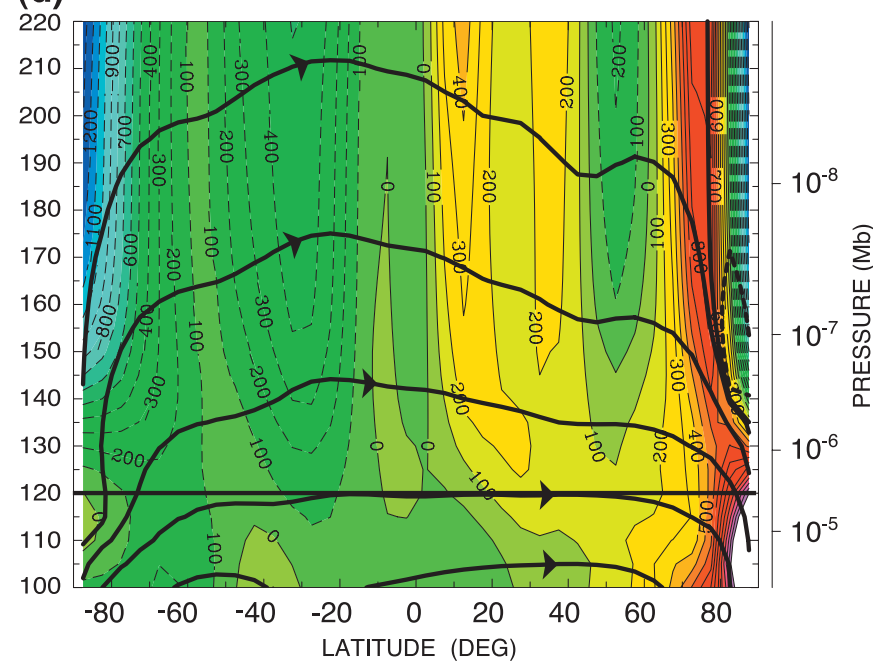

Figure 5. Zonal average neutral temperatures (in Figures 5a and 5b) and adiabatic cooling (in Figures 5c and 5d) for the two solstice seasons, $\mathrm{L}_{S}=090$ and $\mathrm{L}_{S}=270$, as a function of both altitude (vertical axis) and latitude (horizontal axis). The vertical dust mixing height parameter, $\nu=0.03$, is held constant for these simulations, as is the total integrated dust opacity $\tau=1.0$ and solar flux $F_{10.7-\mathrm{cm}}=130$. The black horizontal line in all plots represents $120 \mathrm{~km}$ altitude level. Neutral temperatures (in K) are depicted for the various lower atmospheric dust mixing heights: (a) $\mathrm{L}_{S}=090$ and (b) $\mathrm{L}_{S}=270$. Similarly, the adiabatic heating and cooling contours (in K/day) and the overlain meridional stream functions are depicted for the two solstice seasons: (c) $\mathrm{L}_{S}=090$ and (d) $\mathrm{L}_{S}=270$. The neutral stream functions are dimensionless and are indicative of the zonal averaged flow directions. The maximum zonal averaged meridional winds at $120 \mathrm{~km}$ in Figures $5 \mathrm{c}$ and $5 \mathrm{~d}$ are $-110 \mathrm{~m} / \mathrm{s}$ and $140 \mathrm{~m} / \mathrm{s}$, respectively.

panels remains the seasonally adjusted orbital distance and subsolar latitude. At $\mathrm{L}_{S}=270$, Mars is at perihelion, which results in greater solar insolation for a given lower atmospheric dust distribution. Hence, a priori, one should anticipate a greater response in the lower thermosphere at $\mathrm{L}_{S}=270$ than at $\mathrm{L}_{S}=090$.

[41] As can be seen by comparing Figures $5 \mathrm{~b}$ and $5 \mathrm{~d}$ with Figures $5 \mathrm{a}$ and $5 \mathrm{c}$, the seasonally increased solar heating produces a concomitantly larger winter polar warming feature in the winter lower thermosphere (northern latitudes now). Again selecting the $120 \mathrm{~km}$ altitude level in Figure 5b, temperatures begin at $132 \mathrm{~K}$ near the equator. Moving toward the northern winter pole, temperatures slowly rise until $60^{\circ} \mathrm{N}$ when the temperatures rapidly begin to climb to a polar temperature of $205 \mathrm{~K}$. This represents a polar warming feature of nearly $73 \mathrm{~K}$, in contrast to the winter polar warming feature of $40 \mathrm{~K}$ at the opposite season (see Table 1). Similarly, adiabatic heating in the thermosphere is greatly enhanced in the winter polar regions in the perihelion season of Figure 5d (peak heating of $1300 \mathrm{~K} /$ day at $120 \mathrm{~km})$ compared with that of the aphelion season of Figure $5 \mathrm{c}$ (peak heating of $700 \mathrm{~K} /$ day at $120 \mathrm{~km}$ ).

[42] The zonal average circulation again explains the intensification of the adiabatic heating term in the polar thermosphere. Figure 5d possesses meridional winds up to $140 \mathrm{~m} / \mathrm{s}$, while Figure 5c possesses meridional flows of up to $-120 \mathrm{~m} / \mathrm{s}$. This difference in wind magnitudes again matches the discrepancy in adiabatic heating and cooling 

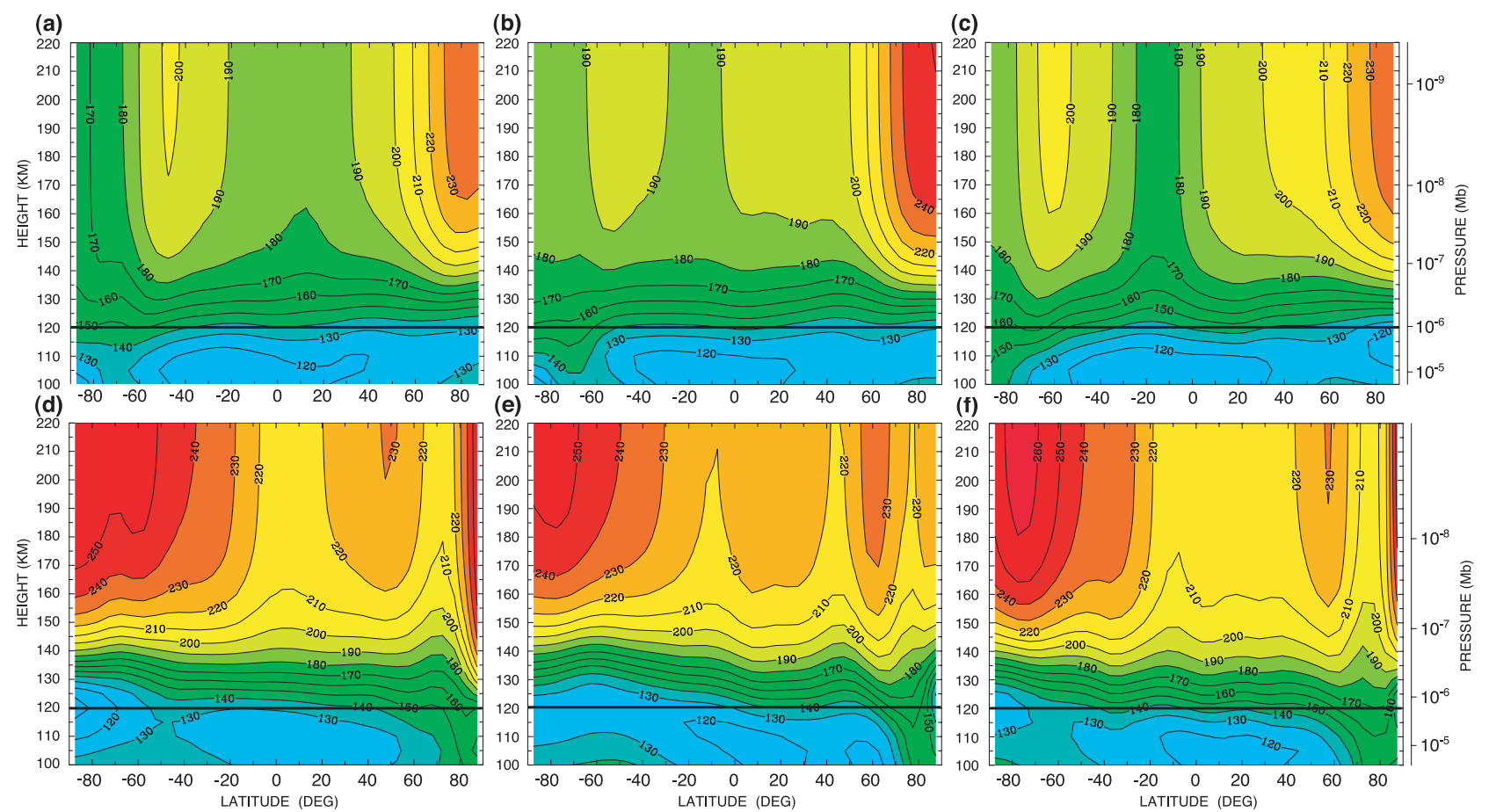

Figure 6. Zonal average neutral temperatures for both solstice seasons at each of the three TES Mapping Years as a function of both altitude (vertical axis) and latitude (horizontal axis). The solar flux is held constant at $\mathrm{F}_{10.7-\mathrm{cm}}=130$ for all simulations. The black horizontal line in all plots represents $120 \mathrm{~km}$ altitude level. Neutral temperatures (in K) for the northern summer solstice, $\mathrm{L}_{S}=090$, are depicted for the various lower atmospheric dust (see Figure 1) TES Maps: (a) TES Year 1, (b) TES Year 2, and (c) TES Year 3. Similarly, neutral temperatures (in K) for the opposite season of southern summer solstice, $\mathrm{L}_{S}=$ 270, are depicted for the various lower atmospheric dust TES Maps: (d) TES Year 1, (e) TES Year 2, and (f) TES Year 3.

between these two simulations. Thus we again find that the interhemispheric Hadley circulation is consistent with the structures seen in the adiabatic heating in the winter polar temperatures. Further, this seasonal enhancement of the winter polar warming during $\mathrm{L}_{S}=270$ (perihelion) is a general trend found for all variations in lower atmospheric vertical dust mixing height, total lower atmosphere dust opacity, and solar flux. However, again, for the sake of brevity we provide only a single case to illustrate a more universal trend.

\subsection{Brief Summary of the Vertical Dust Mixing Study}

[43] In this section, we establish, through numerical experiments using the coupled MGCM-MTGCM, a causal relationship between the lower atmospheric dust distribution and the thermosphere's response. Specifically, we have shown that the adiabatic heating and cooling rates, resulting from the zonal mean circulation, link the simulated thermospheric temperatures and densities to variations in the lower atmospheric vertical dust mixing altitude. Furthermore, this circulation is modified by the extent of the vertical dust mixing, the total integrated lower atmospheric dust, and the season. Table 1 summarizes the polar warming features produced by the MTGCM as a function of the major variables of this numerical experiment.

[44] Finally, although this study addresses many of the variables that could be encountered in the Martian atmo- sphere, some key variables are not directly addressed here: solar flux variations, and non-uniform lower atmospheric dust distributions. We acknowledge that solar flux variations are key to approximating the temperatures and densities observed by in situ measurements. As noted in section 1, solar EUV variations do not significantly impact the energy balance at $120 \mathrm{~km}$. Furthermore, in this study, we are not directly comparing MTGCM outputs with known data sets. Instead, we merely explore the underlying linkage between the upper and lower atmospheres, through this dust-driven interhemispheric Hadley circulation. In the following section, we build upon this dust sensitivity study by investigating the response of the lower thermosphere to non-uniform variations in the lower atmospheric dust distribution in latitude, longitude, and mixing height using TES dust opacity maps.

\section{Interannual Variations in the Mars Lower Thermosphere}

[45] Next, we catalogue the year to year variability of winter polar warming in the MGCM-MTGCM lower thermosphere, using the three available years of TES IR dust opacity data. Beginning with TES mapping year 1 (Mars Year 24-25), we compare the differences between this simulation and the corresponding fields generated from mapping years 2 (Mars Year 25-26) and 3 (Mars Year 

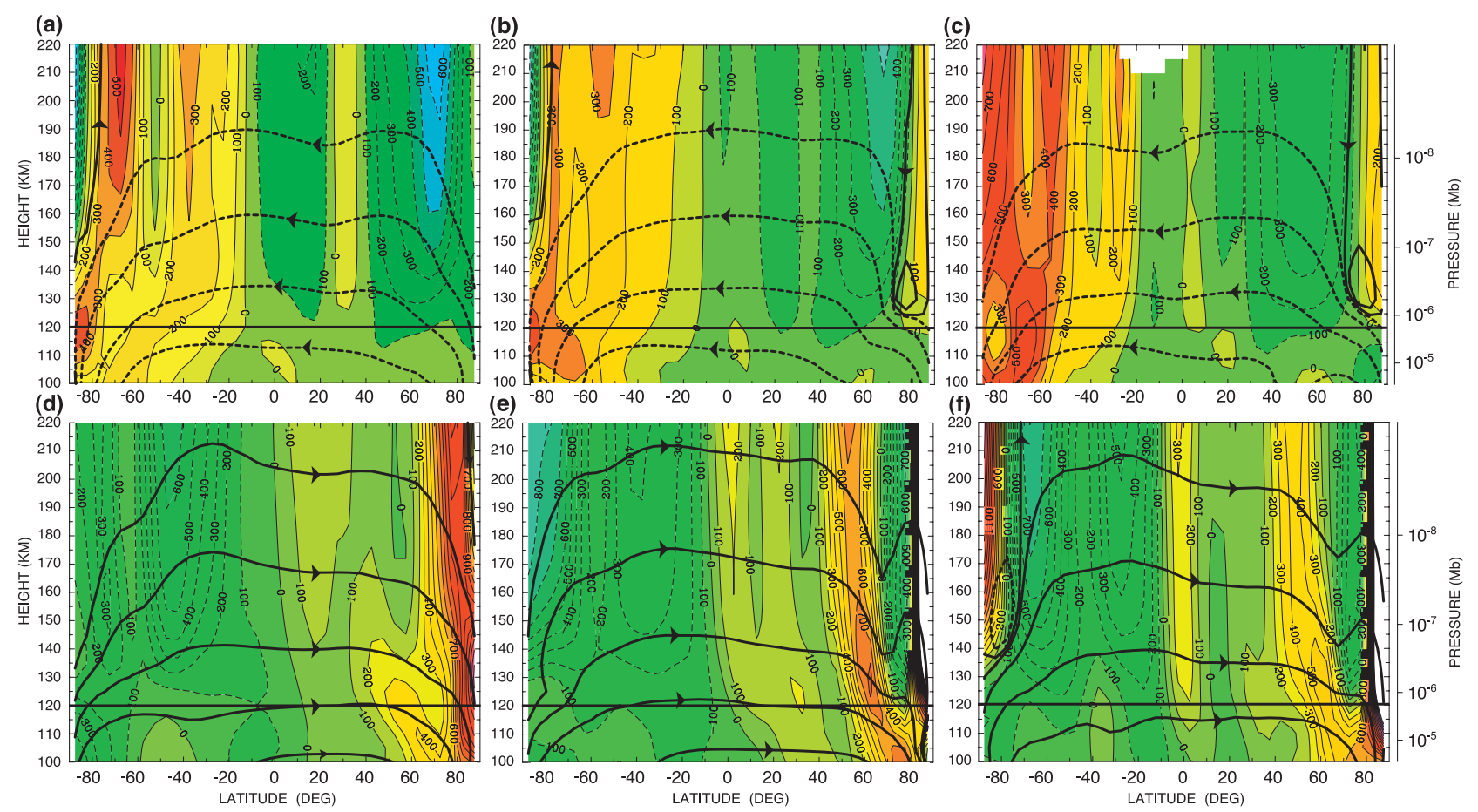

Figure 7. Zonal average adiabatic heating and cooling in (colored contours) and zonal mean stream functions (black lines) for both solstice seasons at each of the three TES Mapping Years as a function of both altitude (vertical axis) and latitude (horizontal axis). The solar flux is held constant at $\mathrm{F}_{10.7-\mathrm{cm}}=130$ for all simulations. The black horizontal line in all plots represents $120 \mathrm{~km}$ altitude level. Adiabatic heating and cooling rates (in $\mathrm{K} /$ day) and meridional stream functions (black contours with directional arrows) for the northern summer solstice, $\mathrm{L}_{S}=090$, are depicted for the various lower atmospheric dust (see Figure 1) TES Maps: (a) TES Year 1 (maximum meridional wind at $120 \mathrm{~km}$ of $-100 \mathrm{~m} / \mathrm{s}$ ), (b) TES Year 2 (maximum meridional wind at $120 \mathrm{~km}$ of $-90 \mathrm{~m} / \mathrm{s}$ ), and (c) TES Year 3 (maximum meridional wind at $120 \mathrm{~km}$ of $-120 \mathrm{~m} / \mathrm{s}$ ). Similarly, adiabatic heating/cooling (in K/day) and zonal mean stream functions for the opposite season of southern summer solstice, $\mathrm{L}_{S}=270$, are depicted for the various lower atmospheric dust TES Maps: (d) TES Year 1 (maximum meridional wind at $120 \mathrm{~km}$ of $130 \mathrm{~m} / \mathrm{s}$ ), (e) TES Year 2 (maximum meridional wind at $120 \mathrm{~km}$ of $150 \mathrm{~m} / \mathrm{s}$ ), and (f) TES Year 3 (maximum meridional wind at $120 \mathrm{~km}$ of $120 \mathrm{~m} / \mathrm{s}$ ). Note that the neutral stream functions are dimensionless and are indicative of the zonal averaged flow directions.

26-27). Although we limit ourselves to analyzing only the two solstice seasons, $\mathrm{L}_{S}=90$ and $\mathrm{L}_{S}=270$, the simulations should provide lower and upper bounds, respectively, for expected variations in the Martian upper atmosphere. In Figures 6-8, zonal mean quantities are displayed, which allow the discussion to focus on the integrated response of the lower thermosphere, rather than on small but potentially significant topographically-driven perturbations. Furthermore, as in the sensitivity study, we focus our discussion on the variations found at an altitude of $120 \mathrm{~km}$ for the same primary reasons: (1) it remains an altitude critical to aerobraking missions in the lower thermosphere, and (2) it represents a relatively good proxy for describing the dynamics of the lower thermosphere $(100-130 \mathrm{~km})$. Finally, we again restrict ourselves to a solar moderate flux of $F_{10.7-\mathrm{cm}}=130$.

\subsection{TES Mapping Years 1-3: Neutral Temperatures}

[46] Figure 6 illustrates zonal mean plots for the MTGCM-MGCM neutral temperature during all three TES Mapping years, during both solstice seasons. On the same figures, the $120 \mathrm{~km}$ altitude level has been delimited with a black horizontal line. The zonal mean lower atmospheric dust content for each of the TES Mapping years can be found in Figure 1. In the discussions that follow, we emphasize the winter polar warming features, as they remain one of the most prominent structures in the lower thermosphere.

\subsubsection{Neutral Temperatures: $\mathrm{L}_{S}=\mathbf{9 0}$}

[47] The MTGCM thermosphere temperatures for $\mathrm{L}_{S}=$ 090 at each of the three TES Years are shown in Figures $6 \mathrm{a}-$ 6c. Starting with TES Year 1, Figure 6a, we follow the $120 \mathrm{~km}$ marker from the equatorial latitudes to the southern winter polar thermosphere. At the equator, temperatures start at $140 \mathrm{~K}$, dropping to a minimum of $137 \mathrm{~K}$ near $20^{\circ} \mathrm{S}$ latitude. Temperatures then warm into the polar thermosphere up to maximum of $151 \mathrm{~K}$ near $63^{\circ} \mathrm{S}$, subsequently dropping to near $147 \mathrm{~K}$ near the pole. This provides a min-to-max deviation of $\Delta \mathrm{T}=14 \mathrm{~K}$ for TES Mapping Year 1.

[48] Figure $6 \mathrm{~b}$ illustrates MTGCM thermosphere temperatures at the same season during TES Mapping Year 2. In 
(a)

(b)
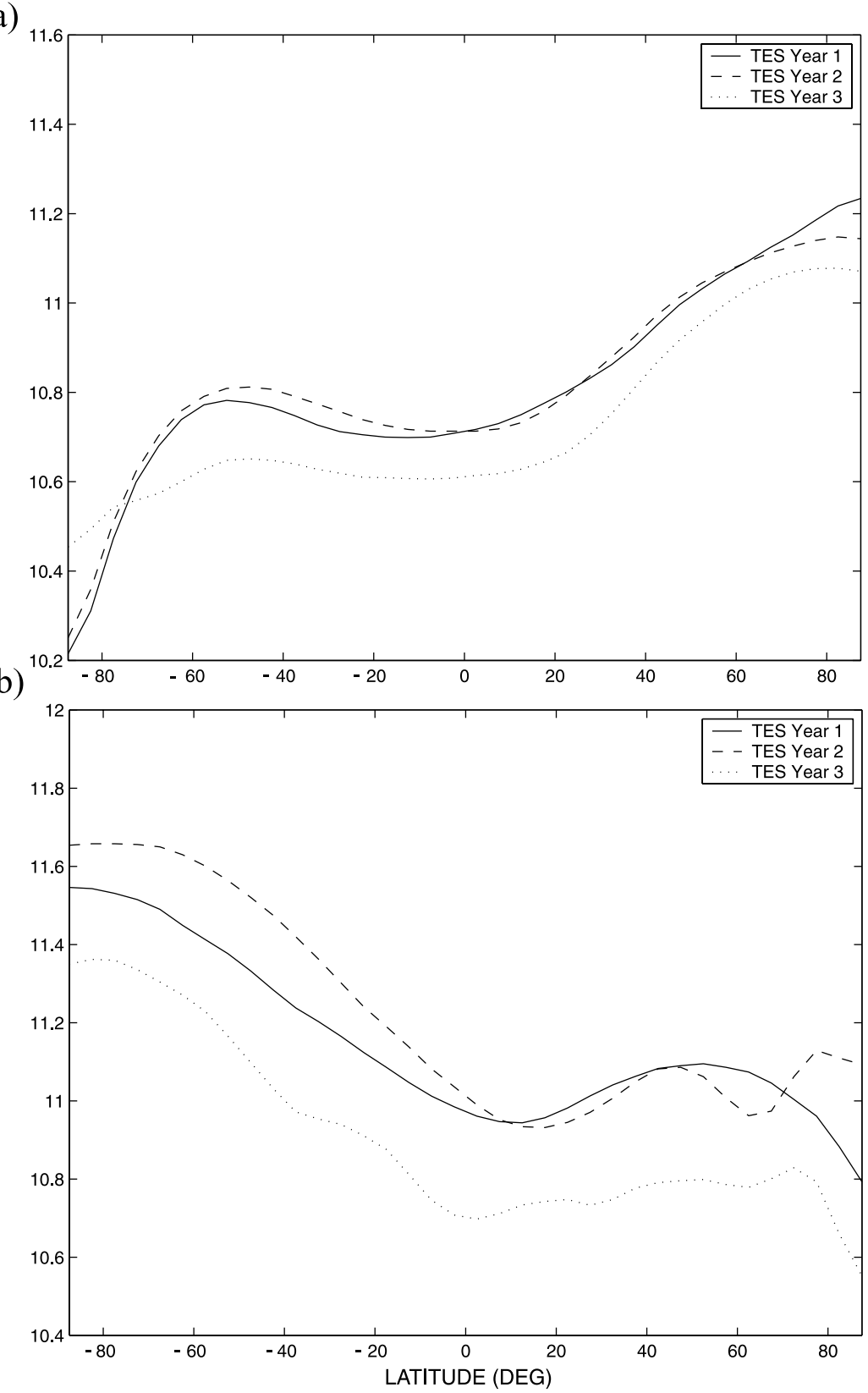

Figure 8. Line plots of the zonal averaged $\log _{10} \mathrm{~cm}^{-3}$ neutral densities at $120 \mathrm{~km}$ for both solstice seasons for each of the three TES Mapping Years as a function of latitude (horizontal axis). The solar flux is held constant at $\mathrm{F}_{10.7-\mathrm{cm}}=130$ for all simulations. Figure 8a represents the aphelion season $\left(\mathrm{L}_{S}=90\right)$ for each of the TES Mapping years, each represented by a different line style (see legend). Figure $8 \mathrm{~b}$ is structured identically for the opposite season of perihelion $\left(\mathrm{L}_{S}=270\right)$. All neutral densities are depicted in units of $\log _{10} \mathrm{~cm}^{-3}$. The density trends shown should be compared with lower atmospheric dust variations shown in Figure 1.

this figure, at $120 \mathrm{~km}$ temperatures begin at $141 \mathrm{~K}$ at the equator. Moving toward the winter polar thermosphere, a local temperature minimum of $138 \mathrm{~K}$ occurs at $28^{\circ} \mathrm{S}$ latitude. Temperatures then increase into the polar thermosphere to a maximum temperature of $157 \mathrm{~K}$. This produces a min-to-max polar warming of $\Delta \mathrm{T}=19 \mathrm{~K}$.

[49] In a similar fashion, Figure 6c illustrates MTGCM thermosphere temperatures at the $\mathrm{L}_{S}=90$ season during TES Mapping Year 3. In this figure, at $120 \mathrm{~km}$ temperatures begin at $142 \mathrm{~K}$ at the equator. Moving toward the winter polar thermosphere, a local temperature minimum of $138 \mathrm{~K}$ occurs at $19^{\circ} \mathrm{S}$ latitude. Temperatures then increase into the polar thermosphere, reaching a maximum temperature of $162 \mathrm{~K}$. This produces a min-to-max polar warming of $\Delta \mathrm{T}=$ $24 \mathrm{~K}$.

5.1.2. Neutral Temperatures: $L_{S}=\mathbf{2 7 0}$

[50] The MTGCM thermosphere temperatures for the opposite season of $\mathrm{L}_{S}=270$ at each of the three TES Years 
Table 2. Polar Warming Features in Kelvin for Interannual Study

\begin{tabular}{llll}
\hline Season & TES Year 1 & TES Year 2 & TES Year 3 \\
\hline $\mathrm{L}_{S}=090$ & $\Delta \mathrm{T}=14 \mathrm{~K}$ & $\Delta \mathrm{T}=19 \mathrm{~K}$ & $\Delta \mathrm{T}=24 \mathrm{~K}$ \\
$\mathrm{~L}_{S}=270$ & $\Delta \mathrm{T}=31 \mathrm{~K}$ & $\Delta \mathrm{T}=35 \mathrm{~K}$ & $\Delta \mathrm{T}=30 \mathrm{~K}$ \\
\hline
\end{tabular}

are shown in Figures $6 \mathrm{~d}-6 \mathrm{f}$. Starting with TES Year 1, Figure $6 \mathrm{~d}$, we again follow the $120 \mathrm{~km}$ marker from the equatorial latitudes to the northern winter polar thermosphere. At the equator, temperatures start at $131 \mathrm{~K}$, which is also the local temperature minimum at $120 \mathrm{~km}$. Temperatures then warm into the northern polar thermosphere up to maximum of $163 \mathrm{~K}$ near $83^{\circ} \mathrm{N}$, subsequently dropping to near $160 \mathrm{~K}$ near the pole. This provides a min-to-max deviation of $\Delta \mathrm{T}=31 \mathrm{~K}$ for TES Mapping Year 1 .

[51] Figure 6e illustrates MTGCM thermosphere temperatures at the same season during TES Mapping Year 2. In this figure, at $120 \mathrm{~km}$ temperatures begin at $130 \mathrm{~K}$ at the equator, which again represents the local temperature minimum. Temperatures then increase into the northern polar thermosphere to a maximum temperature of $165 \mathrm{~K}$. This produces a min-to-max polar warming of $\Delta \mathrm{T}=35 \mathrm{~K}$.

[52] In a similar fashion, Figure 6f illustrates MTGCM thermosphere temperatures at the $\mathrm{L}_{S}=270$ season during TES Mapping Year 3. In this figure, at $120 \mathrm{~km}$ temperatures begin at $142 \mathrm{~K}$ at the equator. Moving toward the northern winter polar thermosphere, the temperatures reach a local minimum of $140 \mathrm{~K}$ at $21^{\circ} \mathrm{N}$ latitude. Temperatures then increase into the polar thermosphere to a maximum temperature of $170 \mathrm{~K}$ at $78^{\circ} \mathrm{N}$ latitude. This produces a min-tomax polar warming of $\Delta \mathrm{T}=30 \mathrm{~K}$.

5.1.3. Temperatures and Dust Levels: A Connection?

[53] Next, having looked at the polar warming features for all three TES Mapping Years at both solstice periods, it proves useful to look at the lower atmospheric dust levels at these same time periods. First, during the $\mathrm{L}_{S}=090$ seasons of each year, the dust levels in Figure 1 appear relatively low. However, $\mathrm{L}_{S}=090$ during TES Year 1 appears very clear of dust, whereas there exists an enhancement of integrated dust opacity in the southern latitudes during TES Year 2 over the previous year's levels. Finally, although continuous dust opacity data is being lost at this time period, during $\mathrm{L}_{S}=090$ of TES Year 3, there exist signs of elevated dust opacity, indicated by the green contours, reaching to mid-latitudes. Therefore, in order of increasing lower atmospheric dust content at aphelion, the TES mapping years are sorted as follows: (1) TES Year 1 $(\Delta \mathrm{T}=14 \mathrm{~K}),(2) \mathrm{TES}$ Year $2(\Delta \mathrm{T}=19 \mathrm{~K})$, and (3) TES Year $3(\Delta \mathrm{T}=24 \mathrm{~K})$. From this sorting by lower atmospheric dust content, a strong correlation emerges between the lower atmosphere dust opacity and the strength of the winter polar warming feature found in the MTGCM thermal structures at $\mathrm{L}_{S}=090$.

[54] During the opposite season, $\mathrm{L}_{S}=270$, a similar trend may be established. The summer solstice season of TES Year 1 is found to have a polar warming feature of $\Delta \mathrm{T}=$ $31 \mathrm{~K}$, which remains very close to that of TES Year 3's polar warming of $\Delta \mathrm{T}=30 \mathrm{~K}$. A quick glance at Figure 1 implies an explanation. The dust opacities in the lower atmosphere appear to be nominally the same for the southern summer solstice season, $\mathrm{L}_{S}=270$, of both mapping years. These results again suggest a significant correlation between the lower atmospheric dust levels and the character of the winter polar warming features in the MTGCM lower thermosphere. By contrast, Figure 1 shows the lower atmosphere recovering from a global dust storm during TES Year 2 at $\mathrm{L}_{S}=270$. In this instance, dust opacity levels remain elevated relative to those of TES Years 1 or 3 at perihelion. This enhanced period of lower atmospheric dust content coincides with the strongest winter polar warming feature found at this season in the MTGCM temperature structures, $\Delta \mathrm{T}=35 \mathrm{~K}$. Taken together, the correlation between neutral temperatures at both solstice periods and lower atmospheric dust seems compelling. This connection between interannual variability in winter polar warming and lower atmospheric dust content can be further supported by examining the remaining key diagnostic outputs from the MTGCM for the same time periods of the same mapping years.

\subsection{TES Mapping Years 1-3: Adiabatic Heating and Cooling Rates}

[55] Figure 7 contains the adiabatic heating and cooling rates at both the $\mathrm{L}_{S}=090$ season (Figures $7 \mathrm{a}-7 \mathrm{c}$ ) and the $\mathrm{L}_{S}$ $=270$ season (Figures $7 \mathrm{~d}-7 \mathrm{f}$ ). In this figure, the first noticeable trend is that the general circulation, as depicted by the stream lines, predominantly flows from the summer hemisphere to the winter hemisphere. Additionally, due to this interhemispheric circulation, the adiabatic term warms the winter polar thermosphere, while concomitantly cooling the summer polar thermosphere. These general observations hold for all TES Mapping years and at both solstice seasons. However, all generalities fail at some level, and we find some structures that do not correspond with this general trend. For instance, Figures $7 \mathrm{~b}, 7 \mathrm{c}$, and $7 \mathrm{f}$ all possess some return flow downward into the summer polar thermosphere, which is accompanied by a simultaneous warming of the summer polar thermosphere. These deviations, however, only represent small modifications to a summer-to-winter interhemispheric Hadley circulation that dominates the thermosphere, as shown in the panels of Figure 7.

[56] Next, as was done in the temperature structures of Figure 6, it is instructive to compare the adiabatic driving terms between the different TES Years in order to expose an underlying correlation with the deviations found earlier in the winter polar warming temperature features contained in Table 2. Focusing first on Figures $7 \mathrm{a}, 7 \mathrm{~b}$, and $7 \mathrm{c}$, we find the adiabatic heating and cooling rates for the $\mathrm{L}_{S}=090$ season for TES Years 1, 2, and 3, respectively. In Figure 7a, the adiabatic heating term in the winter polar thermosphere is positive and broad, spanning $20^{\circ} \mathrm{S}-90^{\circ} \mathrm{S}$ with a peak heating at $120 \mathrm{~km}$ of $400 \mathrm{~K} /$ day near the winter polar region.

[57] Similarly, Figure 7b has a broad warming feature over the same latitudes. However, the regions nearest the winter pole are noticeably enhanced, possessing a broad contour of $300 \mathrm{~K} /$ day warming and peaking at $400 \mathrm{~K} /$ day near the winter polar region. As shown in Table 2, this region of enhanced warming correlates with the increased polar warming features seen at TES Year 2 relative to TES Year 1 during $\mathrm{L}_{S}=090$. 
Table 3. Winter Polar Neutral Densities for Interannual Study

\begin{tabular}{llll}
\hline Season & TES Year 1 & TES Year 2 & TES Year 3 \\
\hline $\mathrm{L}_{S}=090$ & $\rho=1.6 \times 10^{10} \mathrm{~cm}^{-3}$ & $\rho=1.8 \times 10^{10} \mathrm{~cm}^{-3}$ & $\rho=2.8 \times 10^{10} \mathrm{~cm}^{-3}$ \\
$\mathrm{~L}_{S}=270$ & $\rho=6.3 \times 10^{10} \mathrm{~cm}^{-3}$ & $\rho=1.3 \times 10^{11} \mathrm{~cm}^{-3}$ & $\rho=4.0 \times 10^{10} \mathrm{~cm}^{-3}$ \\
\hline
\end{tabular}

[58] Finally, Figure 7c contains the zonal mean adiabatic heating and cooling rates for TES Year 3. At $120 \mathrm{~km}$ near the winter polar latitudes (south), enhancement of the adiabatic heating term remains evident, possessing a peak warming of up to $500 \mathrm{~K} /$ day near $65^{\circ} \mathrm{S}$ latitude. Additionally, the entire region south of $60^{\circ} \mathrm{S}$ latitude contains enhanced warming relative to the other two TES Years at aphelion. Thus we find that this aphelion season during TES Year 3 possesses the greatest winter polar warming feature in Table 2. Thus it remains evident that the polar warming features simulated for aphelion conditions (southern winter solstice) for the three available TES mapping years correlate well with the adiabatic heating and cooling rates found in the MGCM-MTGCM.

[59] In an analogous manner for the opposite season of $\mathrm{L}_{S}=270$, we can compare the adiabatic source term found in Figures $7 d-7 f$. In Figure $7 d$, the adiabatic warming feature spans latitudes from $50^{\circ} \mathrm{N}-90^{\circ} \mathrm{N}$ with peak adiabatic heating at $120 \mathrm{~km}$ of nearly $1200 \mathrm{~K} /$ day near the pole. For the next TES Mapping year shown in Figure 7e, there exist two vertical columns of adiabatic heating. The first column occurs at lower latitudes and possesses a maximum heating of $700 \mathrm{~K} /$ day. The second vertical column of adiabatic heating reaches values of $1400 \mathrm{~K} /$ day at $120 \mathrm{~km}$. Gradients in the adiabatic heating in the polar region of this figure are strong and positive at the northern winter pole. This increased heating between Figures $7 d$ and 7 e correlates with the increased polar warming features seen in the temperatures of Table 2. Lastly, Figure $7 f$ contains the adiabatic heating and cooling rates for the perihelion season for TES Year 3. In this figure, the first, mid-latitude adiabatic warming feature peaks at $500 \mathrm{~K} /$ day, while it possesses a global maximum of nearly $1500 \mathrm{~K} /$ day near the winter pole. The polar warming structures for this year and season are the weakest for $\mathrm{L}_{S}=270$. Thus, as was illustrated for $\mathrm{L}_{S}=090$, a clear correlation between adiabatic heating and the resulting winter polar warming features exists.

\subsection{TES Years 1-3: Neutral Densities}

[60] Figure 8 presents the coupled model's neutral densities for the three TES Years in a format different from that of Figure 4. In Figure 8, the neutral densities at $120 \mathrm{~km}$ are illustrated (in $\log _{10} \mathrm{~cm}^{-3}$ ) for each TES Mapping Year and each solstice season as a function of latitude. Not surprisingly, the densities follow the general trends established with the corresponding neutral temperatures.

[61] Beginning with Figure 8a, TES Year 1 (the solid black line) densities begin at the equator with a value of $5.0 \times 10^{10} \mathrm{~cm}^{-3}$. These neutral densities rise until reaching a maximum of nearly $6.0 \times 10^{10} \mathrm{~cm}^{-3}$ near $55^{\circ} \mathrm{S}$ latitude $(\mathrm{a}$ rise of approximately $20.0 \%$ ). The densities then decrease into the winter polar latitudes to almost $1.6 \times 10^{10} \mathrm{~cm}^{-3}$. Similarly, focusing on the dashed line in Figure 8a, neutral densities for $\mathrm{L}_{S}=090$ season of TES Year 2 also begin with an equatorial value of $5.0 \times 10^{10} \mathrm{~cm}^{-3}$ and reach a local maximum density of nearly $6.6 \times 10^{10} \mathrm{~cm}^{-3}$ at the latitude of $50^{\circ} \mathrm{S}$. This corresponds to percentage density rise of nearly $32.0 \%$ from equatorial values. Similar to the TES Year 1 densities, TES Year 2 densities also drop from this maximum value to nearly $1.8 \times 10^{10} \mathrm{~cm}^{-3}$ at the northern winter pole.

[62] The final TES Mapping Year for aphelion in Figure 8a possesses an equatorial density of $4.0 \times 10^{10} \mathrm{~cm}^{-3}$, which rises to a maximum of nearly $4.5 \times 10^{10} \mathrm{~cm}^{-3}$ at $55^{\circ} \mathrm{S}$, giving a min-to-max percentage density variation of $12.5 \%$. However, for TES Year 3, the densities do not drop as rapidly into the polar regions, reaching a value of $2.8 \times$ $10^{10} \mathrm{~cm}^{-3}$ in the southern winter pole. This last case represents an enhancement of winter polar densities over that of TES Years 1 and 2. This same season during TES Year 3 also exhibited the strongest polar warming signature in temperatures, as shown in Table 2.

[63] At the opposite perihelion season $\left(\mathrm{L}_{S}=270\right)$, Figure $8 \mathrm{~b}$, similar trends in the neutral densities are apparent. For TES Year 1 (the solid black line), neutral densities begin at the equator $1.0 \times 10^{11} \mathrm{~cm}^{-3}$ and reach a maximum value of $1.2 \times 10^{11} \mathrm{~cm}^{-3}$ at $55^{\circ} \mathrm{N}$ latitude, corresponding with a density variation of $20.0 \%$. TES Year 2 likewise possesses a minimum density of $1.0 \times$ $10^{11} \mathrm{~cm}^{-3}$, rising to nearly $1.4 \times 10^{11} \mathrm{~cm}^{-3}$ at $75^{\circ} \mathrm{N}$ latitude. This corresponds to a density variation of nearly $40.0 \%$. Interestingly enough, the densities for this year and season rise into the winter polar regions (reaching $1.3 \times$ $10^{11} \mathrm{~cm}^{-3}$ at the northern pole), which also possesses the greatest winter polar warming feature in Table 2. Finally, the dotted line in Figure 8b (TES Year 3) shows densities increasing from an equatorial density of $5.0 \times 10^{10} \mathrm{~cm}^{-3}$ up to nearly $6.7 \times 10^{10} \mathrm{~cm}^{-3}$ near $75^{\circ} \mathrm{N}$, corresponding to a density variation of $34.0 \%$. This last simulation possesses winter polar neutral densities of $4.0 \times 10^{10} \mathrm{~cm}^{-3}$.

[64] A final examination of Figure 8 and Table 3 reveals a systematic correlation between variations in winter polar densities and variations in lower atmospheric dust levels. Table 2 reveals that the greatest temperature perturbations occur during the $\mathrm{L}_{S}=090$ season of TES Year 3 and the $\mathrm{L}_{S}=270$ season of TES Year 2. Similarly, the winter polar densities of Table 3 are maximized during these same time periods. Thus, in conjunction with an increased winter polar warming, winter polar densities at $120 \mathrm{~km}$ are enhanced as lower atmospheric dust content increases. This indicates that the entire winter polar thermosphere responds to an increase in lower atmospheric dust content with enhanced temperatures and densities. Furthermore, as is established in section 4.1.3, these enhancements in winter polar neutral densities cannot be easily explained by the general inflation and contraction of the lower atmosphere alone. Instead, these enhanced winter polar densities appear strongly correlated with the variations in the strength of the inter- 

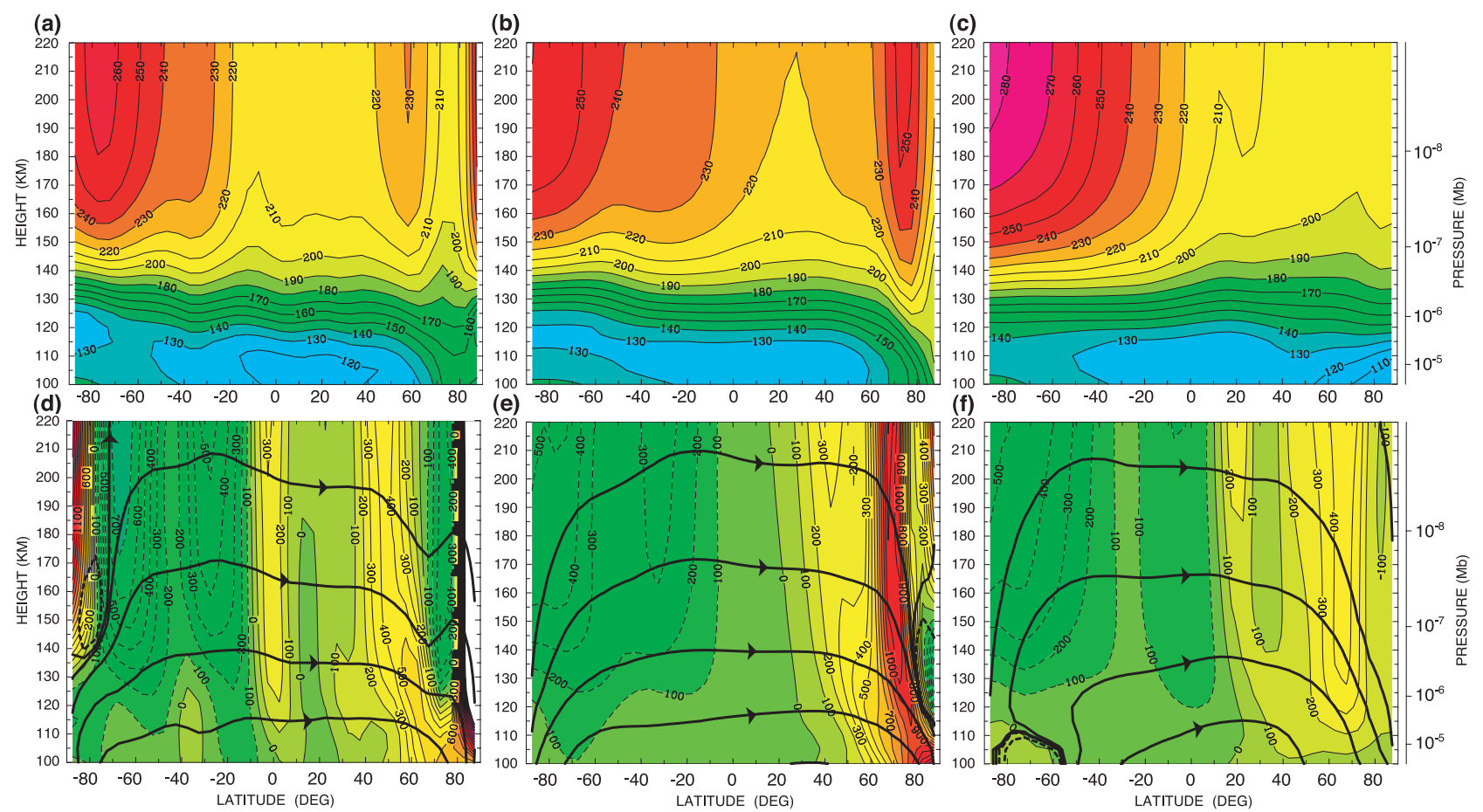

Figure 9. Zonal average neutral temperatures are shown in Figures $9 a-9 c$, while adiabatic heating (positive contours) and cooling (negative contours) are shown in Figures $9 \mathrm{~d}-9 \mathrm{f}$, for the three lower boundary conditions as a function of both altitude (vertical axis) and latitude (horizontal axis). The season is held at $\mathrm{L}_{S}=270$ for all simulations, and solar flux is held at $\mathrm{F}_{10.7-\mathrm{cm}}=130$. The black horizontal line in all plots represents $120 \mathrm{~km}$ altitude level. Neutral temperatures (in K) are depicted for the various lower boundaries employed: (a) fully coupled TES Year 3, (b) diurnally averaged lower boundary, and (c) global averaged fixed lower boundary. Similarly, the adiabatic heating and cooling contours (in K/day) and the overlain meridional stream functions are depicted for the various lower atmospheric boundary conditions: (d) fully coupled TES Year 3, (e) diurnally averaged lower boundary, and (f) global averaged fixed lower boundary. The neutral stream functions are dimensionless and are indicative of the zonal averaged flow directions. The respective maximum meridional winds at $120 \mathrm{~km}$ are (d) $130 \mathrm{~m} / \mathrm{s}$, (e) $170 \mathrm{~m} / \mathrm{s}$, and (f) $85 \mathrm{~m} / \mathrm{s}$.

hemispherical Hadley circulation responsible for winter polar warming.

\section{Response of the MTGCM to Variations in the Lower Boundary Forcing From the MGCM}

\subsection{Describing the Lower Boundary Forcing Study}

[65] In this section, we describe the impact of upward propagating waves and tides from the lower atmosphere on the MTGCM simulated circulation. In order to accomplish this, we employ three different degrees of coupling between the lower and upper atmosphere models. First, we utilize a fully coupled TES Year 3, $\mathrm{L}_{S}=270$ lower boundary, which passes all key parameters $(\mathrm{T}, \mathrm{U}, \mathrm{V}, \mathrm{W}$, and $\Phi)$ at each 2-minute time step of the coupled framework. This coupling scheme, which is identical to that employed in the previous two numerical experiments, allows for a real time upward propagation of migrating and non-migrating tides and planetary waves from the MGCM into the thermosphere of the MTGCM. The resulting temperatures and adiabatic heating/cooling rates from this coupling are illustrated in Figures $9 \mathrm{a}$ and $9 \mathrm{~d}$, respectively, and can be directly compared with Figures 6f and 7f.
[66] For the second part of this study, we employ a diurnally averaged lower boundary condition from the same mapping year and season (TES Year 3 at $\mathrm{L}_{S}=270$ ). By diurnally averaging the lower boundary, we in effect remove the diurnal cycle in the lower atmosphere. Tidal analysis of this diurnally averaged lower boundary indicates that the upward propagating migrating and non-migrating tides are removed from this simulation. However, it is unclear to what degree stationary waves (e.g., Rossby-type wave modes) and low frequency (e.g., baroclinic waves) are impacted by this diurnal averaging process. In all, the primary tidal amplitudes in the thermosphere are drastically reduced by $75-80 \%$ in the winter polar thermosphere. This, in turn, has a significant effect on the resulting MTGCM simulations, as illustrated in Figures $9 \mathrm{~b}$ and 9e.

[67] Finally, for the third part of this investigation, we specify all lower boundary fields at the lowest pressure level in the MTGCM (the 1.32- $\mu$ bar pressure level) with global average values taken from the TES Year 3 lower boundary at $\mathrm{L}_{S}=270$. We fixed these lower boundary parameters at the lowest pressure level to the following: $\mathrm{T}=150 \mathrm{~K}, \mathrm{U}=$ $0.0 \mathrm{~m} / \mathrm{s}, \mathrm{V}=0.0 \mathrm{~m} / \mathrm{s}, \mathrm{W}=0.0 \mathrm{~m} / \mathrm{s}$, and $\Phi=70 \mathrm{~km}$. Tidal analysis of this fixed lower boundary indicates that all 
upward propagating tides and waves from the lower atmosphere are eliminated. This decoupling from the MGCM at the lower boundary has a pronounced impact on the resulting MTGCM simulations, as illustrated in Figures 9c and 9f.

\subsection{Results From the Lower Boundary Forcing Study}

[68] Figures 9a-9f summarize the simulated response of the Martian thermosphere to the three variations in the amount of upward propagating tides described above. In this section, we point out the most salient features of this wave-coupling analysis, illustrating the influence that the lower atmosphere has upon the dynamics of the upper atmosphere.

[69] Figure 9a contains the temperature structure for the fully coupled TES Year 3 simulation at perihelion. Figure 9d contains the adiabatic heating and cooling rates (contours) with the overlying meridional stream function for this same year and season. Because this simulation was discussed in detail in the section on interannual variations, we now point out only the most salient features of the dynamics here. First, as indicated by the meridional streamlines of Figure 9d, the circulation has access to the winter polar latitudes (poleward of $70^{\circ} \mathrm{N}$ ). Similarly, the greatest adiabatic heating occurs at the winter pole, with an amplitude in excess of $1600 \mathrm{~K} /$ day at $87.5^{\circ} \mathrm{N}$. This peak of adiabatic heating corresponds to the steep thermal gradient at the northern winter pole seen in Figure 9a.

[70] The thermosphere's responses to a diurnally averaged lower boundary condition are depicted in Figures 9b and 9e. In this simulation, the upward propagating tides are greatly minimized in comparison with those present in the simulations of Figures 9a and 9d. This reduction in the tidal amplitudes results in a circulation that does not penetrate as deeply into the winter polar latitudes, as shown in Figure 9e. Instead, the meridional flow is redirected to lower latitudes, resulting in the adiabatic warming found between $60^{\circ} \mathrm{N}$ and $80^{\circ} \mathrm{N}$ of this same panel. This meridional flow is significantly stronger (maximum speed of $170 \mathrm{~m} / \mathrm{s}$ ) than that of Figure 9d (maximum speed of $130 \mathrm{~m} / \mathrm{s}$ ). However, the adiabatic heating in Figure $9 \mathrm{e}$ reaches a peak of only $1200 \mathrm{~K} /$ day versus the $1600 \mathrm{~K} /$ day of Figure 9d. Lower in the thermosphere (below $110 \mathrm{~km}$ ), adiabatic warming does extend to the winter pole.

[71] The adiabatic heating rates for the diurnally averaged lower boundary mirror the resulting temperature structures found in Figure 9b. In Figure 9b, the peak temperature high in the thermosphere is displaced equatorward from the analogous peak in Figure 9a. Additionally, the lowest altitudes of Figure 9e show an increased winter polar warming feature due to the displaced adiabatic heating at these altitudes. Thus it appears that, by minimizing the upward propagating tides from the lower atmosphere, the meridional circulation in the thermosphere does not extend to latitudes north of $70^{\circ} \mathrm{N}$, except at the lowest altitudes.

[72] Finally, Figures 9c and 9f depict the thermosphere's simulated response to the global average fixed lower boundary. At this lower boundary, the temperature and geopotential height are specified at the bottom of the model to $150 \mathrm{~K}$ and $70 \mathrm{~km}$, respectively, while the winds were specified to be zero. Essentially, this represents a "billiard ball" lower atmosphere that remains static throughout the simulation. This figure exhibits significantly weaker meridional winds with maximum velocities of $85 \mathrm{~m} / \mathrm{s}$ and peak adiabatic heating rates of $400 \mathrm{~K} /$ day seen in Figure 9f. Not surprisingly, this weakened circulation does not extend to latitudes poleward of $70^{\circ} \mathrm{N}$, instead depositing most of its energy between $50^{\circ} \mathrm{N}$ and $70^{\circ} \mathrm{N}$. This weak circulation results in the temperature structures of Figure 9c, which shows virtually no winter polar warming signatures in the thermosphere.

\subsection{Brief Summary of the Lower Boundary Comparison}

[73] Through a systematic comparison of Figures $9 a-9 c$ with Figures 9d-9f, some key results emerge. First, by removing or severely damping out upward propagating tides, as was done in the diurnally averaged and billiard ball cases, the meridional circulation does not extend to latitudes poleward of $70^{\circ} \mathrm{N}$. This result remains consistent with analogous work by Wilson [1997], which finds that upward propagating tides allow lower atmospheric meridional circulation to extend to latitudes poleward of $70^{\circ}$, contributing to winter polar warming in the lower atmosphere. Moreover, this result in the thermosphere appears even more impressive given that, at perihelion $\left(\mathrm{L}_{S}=270\right)$, the calculated meridional circulation exhibits a seasonal maximum, meaning that it should have the greatest opportunity of accessing the winter polar latitudes.

[74] Second, by employing the billiard ball lower boundary condition, we eliminate the lower atmosphere's contribution to the circulation that is responsible for the thermosphere's winter polar warming features. The resulting simulations exhibit a weakened meridional circulation, which in turn produces very weak winter polar warming features in the thermosphere. This suggests that the interhemispheric Hadley circulation responsible for strong thermosphere winter polar warming originates in the lower atmosphere and couples with an in situ solar EUV driven thermospheric circulation. This combined Hadley circulation results in the adiabatic heating and cooling rates that, in turn, produce the temperature and density structures consistent with winter polar warming in the lower thermosphere. In effect, this last lower boundary simulation reveals the vertical extent of this Hadley circulation and clearly suggests that winter polar warming in the lower thermosphere is a whole atmosphere response, rather than an effect driven by an in situ thermospheric circulation only.

\section{Discussion}

\subsection{Summary of the Three Numerical Investigations}

[75] Throughout this work, we delineate the results from three primary numerical experiments: a study of the thermosphere's sensitivity to lower atmospheric dust distributions, a thermospheric interannual study, and finally a lower boundary study. Through these three investigations, we seek to answer key questions about the physics of the thermosphere and about its degree of coupling with the lower atmosphere.

[76] From the first investigation, the dust sensitivity study, we find that the vertical dust mixing, holding all other variables constant, greatly modifies the simulated winter polar warming features in the MTGCM's thermo- 
sphere. As lower atmospheric dust is mixed to higher altitudes, the winter polar warming features become more pronounced, as shown in Table 1 and Figures 3 and 4. From this table and these figures one finds that, for a constant dust opacity of $\tau=0.3$ and for a constant season of $\mathrm{L}_{S}=090$, the winter polar warming features systematically increase from a $\Delta \mathrm{T}=20 \mathrm{~K}$ for the lowest dust mixing altitude $(\nu=0.3)$ up to a $\Delta \mathrm{T}=37 \mathrm{~K}$ for the highest dust mixing altitude $(\nu=$ $0.005)$. Also, if the lower atmospheric dust's total opacity is increased, given a constant season and a constant dust mixing height, then the winter polar warming increases. This is illustrated for the case when $\mathrm{L}_{S}=090$ and $\nu=0.03$, showing a winter polar warming feature that rises from a $\Delta \mathrm{T}=30 \mathrm{~K}$ for $\tau=0.3$ up to a $\Delta \mathrm{T}=40 \mathrm{~K}$ for $\tau=1.0$. Finally, one finds that perihelion possesses a much greater winter polar warming feature $(\Delta T=73 \mathrm{~K})$, all things begin equal, than that of aphelion $(\Delta \mathrm{T}=40 \mathrm{~K})$.

[77] This sensitivity study clearly points out how lower atmospheric dust systematically impacts the temperatures and densities in the upper atmosphere. Furthermore, this sensitivity investigation demonstrates that an interhemispheric summer-to-winter Hadley circulation dominates the thermosphere's dynamics. Additionally, the resulting adiabatic heating and cooling rates, due to the convergence and divergence of meridional and zonal flows, produce the observed winter polar warming features in the thermosphere temperatures shown in Figure 3. In summary, this first numerical experiment strongly suggests that interhemispheric dust-driven circulation is the primary determinant for the winter polar thermosphere's densities and temperatures. Further, this circulation is also significantly modified by the lower atmosphere's vertical dust mixing height, the total dust opacity, and the season.

[78] The results from the second major numerical investigation, the interannual study, follow naturally from the results of the sensitivity study. First, as Table 2 and Figure 1 indicate, the variations in the temperatures at $120 \mathrm{~km}$ for the three TES mapping years are directly linked with the lower atmospheric dust variations. Essentially, for each TES mapping year, if the lower atmospheric dust content is enhanced, then the simulated thermosphere winter polar warming is enhanced. Illustrating this point more clearly, by sorting the TES Year aphelion seasons $\left(\mathrm{L}_{S}=090\right)$ in order of increasing lower atmospheric dust content, one finds the following: (1) TES Year 1 with a $\triangle \mathrm{T}=14 \mathrm{~K}$, (2) TES Year 2 with a $\Delta \mathrm{T}=19 \mathrm{~K}$, and (3) TES Year 3 with a $\Delta \mathrm{T}=24 \mathrm{~K}$. Similarly, by sorting the perihelion seasons $\left(\mathrm{L}_{S}=270\right)$ for the thee TES years in order of increasing lower atmospheric dust content, we find the following: (1) TES Year 3 has a $\Delta \mathrm{T}=30 \mathrm{~K}$, (2) TES Year 1 has a $\Delta \mathrm{T}=31 \mathrm{~K}$, and (3) TES Year 2 has a $\Delta \mathrm{T}=35 \mathrm{~K}$. This sorting suggests a strong correlation between the lower atmospheric dust levels and the associated winter polar warming signatures.

[79] Second, the perihelion season possesses much greater overall temperature variations, as measured by the winter polar warming, from year to year. At the opposite season of $\mathrm{L}_{S}=090$, the magnitude of the variations, although still significant, are reduced from year to year in comparison to those of $\mathrm{L}_{S}=270$. This indicates an interannual variability of the thermosphere's temperatures consistent with the interannual variations found in the lower atmosphere by Liu et al. [2003].
[80] Third, the winter polar neutral densities at $120 \mathrm{~km}$ in the interannual investigation respond in a manner completely consistent with the sensitivity study's results. As the lower atmospheric dust levels are increased, the winter polar thermosphere neutral densities systematically increase due to an increased heating at lower altitudes, as shown in Figure 8 and Table 3. Ultimately this interannual study confirms that an interhemispheric Hadley circulation and its concomitant adiabatic heating/cooling rates, shown in Figure 7 , to be the primary cause for the variations in the winter polar thermosphere's temperatures and densities.

[81] The third major numerical investigation reveals the vertical extent of this interhemispheric Hadley circulation explored in the earlier two studies. By diurnally averaging the perihelion TES Year 3 lower atmosphere (i.e., turning off the diurnal cycle in the lower atmosphere), we find that the thermosphere's response is greatly modified. The removal of migrating and non-migrating tides reduces the summer-to-winter meridional flow's ability to extend into the thermosphere's winter polar latitudes (poleward of $70^{\circ} \mathrm{N}$ ) of Figure 9, as was found in the lower atmosphere by Wilson [1997]. Furthermore, by removing the lower atmosphere altogether, as was done in the billiard ball case using global average values at the 1.32- $\mu$ bar pressure level, the strong interhemispheric meridional circulation producing the polar warming weakens and the resulting thermosphere winter polar warming features are greatly reduced. This investigation strongly suggests that upward propagating tides are crucial to producing winter polar warming in the thermosphere, and it indicates that this Hadley circulation extends from the lower atmosphere high into the thermosphere.

\subsection{Implications of These Results}

[82] From all three major numerical studies catalogued in this paper, a clear and simple result emerges. In the Martian atmosphere, there exists a dust driven summer-to-winter interhemispheric Hadley circulation, extending from the lower atmosphere to the thermosphere, that removes energy from the summer hemisphere and deposits that energy in the winter hemisphere. This result has profound implications for the aeronomy of Mars and future aerobraking missions to Mars. First, this paper's results indicate that the Mars atmosphere is an intimately coupled system, making it necessary to account fully for the lower atmosphere when modeling the structures of the upper atmosphere. Ignoring this coupling results in simulations that lack the dynamical structures observed in situ.

[83] In addition to having important implications for Martian upper atmospheric science, the results from this paper also possess significance for future aerobraking missions. As the interannual study reveals, the perihelion season, $\mathrm{L}_{S}=270$, experiences the greatest temperature and density enhancements at the winter pole. At the opposite season, $\mathrm{L}_{S}=090$, reduced variations exist, although they remain significant. Hence, if significant variations in the thermosphere's temperatures and densities pose the greatest threat to aerobraking spacecraft, then the aphelion season appears to be most suitable time frame for aerobraking maneuvers in the lower thermosphere. However, the winter polar thermosphere exhibits significant variability in both densities and temperatures at both solstice seasons 
for all years simulated. Moreover, these variations relate directly to lower atmospheric dust levels. Thus aerobraking in the winter polar thermosphere could still expose the spacecraft to significant risks, which remain heavily dependent on the lower atmospheric dust content and distribution.

\section{Future Work}

\subsection{Suggested Future Studies}

[84] The present work and previous studies indicate that the entire Mars atmosphere is an integrated system that is highly coupled dynamically. However, since this work is intended as a baseline theoretical study, we envision several avenues of further research that could directly build upon the results of this investigation.

[85] First, the incorporation of gravity waves into the MGCM-MTGCM is needed to show how these wave features change and modify the interhemispheric Hadley circulation discussed in this work [Forbes and Hagan, 2000; Forbes et al., 2002; Angelats $i$ Coll et al., 2005]. The degree to which the dominant interhemispheric circulation is modified by these smaller scale gravity waves has not been documented in the MGCM-MTGCM. Further, such a numerical experiment would better elucidate the details of the energy balances in the upper atmosphere.

[86] Second, a detailed wave analysis investigation, addressing various components of eddy momentum fluxes, would help quantify the impacts of upward propagating waves and tides on the circulation in the thermosphere. This study should examine how planetary waves and tides shift the latitude at which the interhemispheric Hadley circulation deposits energy. Furthermore, this study could better quantify the contribution of migrating tides to the density perturbations at aerobraking altitudes. Moreover, using the interannual results of this work as a starting point, one could explore the existence of a seasonal modulation of the effectiveness of these waves and tides.

[87] Third, a systematic comparison between MGCMMTGCM outputs and aerobraking data sets would provide a series of constraints against which to test the validity of our simulations. This study could match several possible parameters and compare them with several recent data sets, including the new Mars Reconnaissance Orbiter (MRO) aerobraking and Mars Express (MEX) solar occultation data sets. In such an experiment, more care should be paid to seasonal-specific parameters and solar fluxes in order to reproduce the structures observed.

\subsection{Further Improvements to the Coupled Model}

[88] Finally, the development of a self-consistent groundto-exobase $(0-250 \mathrm{~km})$ model for Mars, along the lines of Angelats $i$ Coll et al. [2005] and González-Galindo et al. [2005, 2006], would allow us to further investigate the coupling between the upper and lower atmospheres. The Global Ionosphere-Thermosphere Model (GITM) of Ridley et al. [2006] is presently being used as a suitable modeling framework within which to develop such a self-consistent Mars total atmosphere model.

[89] Acknowledgments. The authors would like to thank Ben Foster at $\mathrm{HAO} / \mathrm{NCAR}$ for his tireless support and unending assistance. Thanks to Michael Smith of NASA GSFC for graciously allowing us to modify his TES opacity maps in this paper. Also, we would like to thank Jere Justus of
NASA Marshall and the Mars-GRAM project, both of whom gave helpful advice about the model's accuracy. This research was funded by NASA grant NNG04GJ94G to the University of Michigan and by NASA grant NAG5-12123 to New Mexico State University.

\section{References}

Angelats i Coll, M., F. Forget, M. A. López-Valverde, P. L. Read, and S. R. Lewis (2004), Upper atmosphere of Mars up to $120 \mathrm{~km}$ : Mars Global Surveyor accelerometer data analysis with the LMD general circulation model, J. Geophys. Res., 109, E01011, doi:10.1029/2003JE002163.

Angelats i Coll, M., F. Forget, M. A. López-Valverde, and F. GonzálezGalindo (2005), The first Mars thermospheric general circulation model: The Martian atmosphere from the ground to $240 \mathrm{~km}$, Geophys. Res. Lett., 32, L04201, doi:10.1029/2004GL021368.

Bougher, S. W., S. Engel, R. G. Roble, and B. Foster (1999a), Comparative terrestrial planet thermospheres: 2 . Solar cycle variation of global structure and winds at equinox, J. Geophys. Res., 104, 16,591-16,611.

Bougher, S. W., G. M. Keating, R. W. Zurek, J. M. Murphy, R. M. Haberle, J. Hollingsworth, and R. T. Clancy (1999b), Mars Global Surveyor aerobraking: Atmospheric trends and model interpretation, Adv. Space Res., 23(11), 1887-1897.

Bougher, S. W., S. Engel, R. G. Roble, and B. Foster (2000), Comparative terrestrial planet thermospheres: 3 . Solar cycle variation of global structure and winds at solstices, J. Geophys. Res., 105, 17,669-17,689.

Bougher, S. W., S. Engel, D. P. Hinson, and J. R. Murphy (2004), MGS Radio Science electron density profiles: Interannual variability and implications for the Martian neutral atmosphere, J. Geophys. Res., 109, E03010, doi:10.1029/2003JE002154.

Bougher, S. W., J. M. Bell, J. R. Murphy, M. A. López-Valverde, and P. G. Withers (2006), Polar warming in the Mars thermosphere: Seasonal variations owing to changing insolation and dust distributions, Geophys. Res. Lett., 33, L02203, doi:10.1029/2005GL024059.

Christensen, P. R., et al. (2001), Mars Global Surveyor Thermal Emission Spectrometer experiment: Investigation description and surface science results, J. Geophys. Res., 106, 23,823-23,871.

Clancy, R. T., et al. (2000), An intercomparison of ground-based millimeter, MGS TES, and Viking atmospheric temperature measurements: Seasonal and interannual variability of temperatures and dust loading in the global Mars atmosphere, J. Geophys. Res., 105, 9553-9571.

Conrath, B. J. (1975), Thermal structure of the Martian atmosphere during the dissipation of the dust storms of 1971, Icarus, 24, 36-46.

Forbes, J. M., and M. Hagan (2000), Diurnal Kelvin wave in the atmosphere of Mars: Towards an understanding of "stationary" density structures observed by the MGS accelerometer, Geophys. Res. Lett., 27, $3563-3566$

Forbes, J. M., A. F. C. Bridger, S. W. Bougher, M. E. Hagan, J. L. Hollingsworth, G. M. Keating, and J. Murphy (2002), Nonmigrating tides in the thermosphere of Mars, J. Geophys. Res., 107(E11), 5113, doi:10.1029/2001JE001582.

Forget, F., F. Hourdin, and O. Talagrand (1996), Simulation of the Martian atmospheric polar warming with the LMD general circulation model, Ann. Geophys., 14, C797.

Forget, F., F. Hourdin, R. Fournier, C. Hourdin, O. Talagrand, M. Collins, S. R. Lewis, P. L. Read, and J. Huot (1999), Improved general circulation models of the Martian atmosphere from the surface to above $80 \mathrm{~km}$, J. Geophys. Res., 104(E10), 24,155-24,176.

Fox, J. L., and K. Y. Sung (2001), Solar activity variations in the Venus thermosphere/ionosphere, J. Geophys. Res., 106, 21,305-21,335.

Gangale, T., and M. Dudley-Rowley (2005), Issues and options for a Martian calendar, Planet. Space Sci., 53, 1483-1495.

González-Galindo, F., M. A. López-Valverde, M. Angelats i Coll, and F. Forget (2005), Extension of a Martian general circulation model to thermospheric altitudes: UV heating and photochemical models, J. Geophys. Res., 110, E09008, doi:10.1029/2004JE002312.

González-Galindo, F., S. W. Bougher, J. M. Bell, M. A. Lopez-Valverde, and F. Forget (2006), Thermal structure of the Martian thermosphere: LMD-GCM and MTGCM Intercomparisons, paper presented at Mars Atmosphere Modelling and Observations Workshop, Cent. Natl. d'Etudes Spatiales, Granada, Spain, 27 Feb. to 3 March.

Haberle, R. M., M. M. Joshi, J. R. Murphy, J. R. Barnes, J. T. Schofield, G. Wilson, M. Lopez-Valverde, J. L. Hollingsworth, A. F. C. Bridger, and J. Schaeffer (1999), General circulation model simulations of the Mars Pathfinder atmospheric structure investigation/meteorology data, J. Geophys. Res., 104(E4), 8957-8974.

Keating, G. M., et al. (1998), The structure of the upper atmosphere of Mars: In-situ accelerometer measurements from Mars Global Surveyor, Science, 279, 1672-1676.

Keating, G. M., et al. (2002), Detection of north polar winter warming from the Mars Odyssey 2001 accelerometer experiment, paper presented at 
34th Scientific Assembly of the Committee on Space Research (COSPAR) and the World Space Congress, Houston, Tex.

Keating, G. M., et al. (2003), Brief review on the results obtained with the MGS and Mars Odyssey 2001 accelerometer experiments, paper presented at Mars Atmosphere Modelling and Observations, Cent. Natl. d'Etudes Spatiales, Granada, Spain, 13-15 Jan.

Liu, J., M. I. Richardson, and R. J. Wilson (2003), An assessment of the global, seasonal, and interannual spacecraft record of Martian climate in the thermal infrared, J. Geophys. Res., 108(E8), 5089, doi:10.1029/ 2002JE001921.

López-Valverde, M. A., D. P. Edwards, M. López-Puertas, and C. Roldán (1998), Non-local thermodynamic equilibrium in general circulation models of the Martian atmosphere: 1. Effects of the local thermodynamic equilibrium approximation on thermal cooling and solar heating, J. Geophys. Res., 103(E7), 16,799-16,812.

Murphy, J. R., C. B. Leovy, and J. E. Tillman (1990), Observations of Martian surface winds at the Viking lander 1 site, J. Geophys. Res., 95(B9), 14,555-14,576.

Murphy, J. R., R. M. Haberle, O. B. Toon, and J. B. Pollack (1993), Martian global dust storms: Zonally symmetric numerical simulations including size dependent particle transport, J. Geophys. Res., 98(E2), 3197-3220.

Pollack, J. B., R. M. Haberle, J. Schaeffer, and H. Lee (1990), Simulations of the general circulation of the Martian atmsophere: 1. Polar processes, J. Geophys. Res., 95(B2), 1447-1473.

Ridley, A. J., Y. Deng, and G. Toth (2006), The Global IonosphereThermosphere Model, J. Atmos. Sol. Terr. Phys., 68, 839-864.

Roble, R. G., E. C. Ridley, A. D. Richmond, and R. E. Dickinson (1988), A coupled thermosphere/ionosphere general circulation model, Geophys. Res. Lett., 15, 1325-1328.
Sante, M., and D. Crisp (1993), Thermal structure and dust loading of the Martian atmosphere during late southern summer: Mariner 9 revisited, J. Geophys. Res., 93, 3261-3279.

Smith, M. D. (2004), Interannual variability in TES atmospheric observations of Mars during 1999-2003, Icarus, 167, 148-165.

Smith, M. D. (2006), TES Atmospheric Temperature, Aerosol Optical Depth, and Water Vapor Observations 1999-2004, paper presented at Mars Atmosphere Modelling and Observations Workshop, Cent. Natl. d'Etudes Spatiales, Granada, Spain, 27 Feb. to 3 March

Suran, J. (1997), A calendar for Mars, Planet. Space Sci., 45, 705-708.

Theodore, B., E. Lellouch, E. Chassefiere, and A. Hauchecorne (1993), Solstial temperature inversions in the Martian middle atmosphere: Observational clues and 2-D modeling, Icarus, 105, 512-528.

Wilson, R. J. (1997), A general circulation model of the Martian polar warming, Geophys. Res. Lett., 24, 123-126.

Wilson, R. J. (2002), Evidence for nonmigrating thermal tides in the Mars upper atmosphere from the Mars Global Surveyor Accelerometer Experiment, Geophys. Res. Lett., 29(7), 1120, doi:10.1029/2001GL013975.

Withers, P. (2006), Mars Global Surveyor and Mars Odyssey Accelerometer observations of the Martian upper atmosphere during aerobraking, Geophys. Res. Lett., 33, L02201, doi:10.1029/2005GL024447.

Withers, P. G., S. W. Bougher, and G. M. Keating (2003), The effects of topographically-controlled thermal tides in the Martian upper atmosphere as seen by the MGS Accelerometer, Icarus, 164, 14-32.

J. M. Bell and S. W. Bougher, Department of Atmospheric, Oceanic, and Space Sciences, University of Michigan, Space Research Building, 2455 Hayward Drive, Ann Arbor, MI 48109, USA. (jmbell@umich.edu)

J. R. Murphy, Department of Physics and Astronomy, New Mexico State University, MSC 4500, Box 30001, Las Cruces, NM 88003, USA. 